Rhodes, M. E. (1959). J. gen. Microbiol. 21, 221-263

\title{
The Characterization of Pseudomonas fluorescens
}

\author{
BY MURIEL E. RHODES \\ Department of Microbiology, University of Reading
}

SUMMARY: A study of phytopathogenic pseudomonads was begun, but it was found that they could not easily be differentiated from the commonly occurring soil- and water-inhabiting fluorescent pseudomonads. A collection of 169 isolates, including 24 named cultures from various collections, was studied. Both old and new kinds of diagnostic characters, cytological, physiological and biochemical, were investigated under standard conditions. Recordings were made at frequent intervals during a 28-day incubation period. Each character was investigated at least three times during a period of at least five years in order to assess its stability.

A clear differentiation between Pseudomonas hydrophila (NCTC 7810) and $P$. icthyosmia (NCTC 8049) and the rest of the collection was apparent; these two isolates belong to the genus Aeromonas Kluyver \& van Niel. The use of the vibriostatic pteridine derivative $0 / 129$ revealed a close relationship between them and Vibrio icthyodermis PL 1.

Of the 169 isolates (including at least 20 named species) 165 had 26 common definable and stable characters; these are offered for an extended definition of the genus Pseudomonas. A further $\mathbf{4 3}$ characteristics were not common to all 165 isolates. No two of these characters were correlated. One isolate had $42 / 43$ positive characters and one had only 4, and there was a very great range of variation. Among 58 selected isolates there were 21 small groups of identical isolates, but the largest number in any group was 5; the remaining 107 isolates each had a different combination of the 43 characters. Even 10 fluorescent isolates, originally obtained from a single plating of 1 loopful of river water, showed 9 different combinations of characters.

A small group of 5 isolates appeared to conform with Pseudomonas aeruginosa as defined by Haynes (1951) and Gaby (1955) but many fluorescens-type isolates were closely related when considered on the basis of all the characters investigated. Several of the named phytophathogens showed a close relationship, or apparent identity, with soil and water isolates; many phytophathogens, however, had a conspicuous number of negative characters, suggesting loss of adaptability in a more selective environment.

The 134 soil- and water-type isolates had 11 positive characters, and 9 others almost always positive. On this basis, and adopting the view that all these characters merit equal emphasis (see Tanner, 1918; Sneath, 1957 $a, b$ ) it is thought that further divisions into subgroups (species?) are not justified, and that these characters should be used to describe accurately $\boldsymbol{P}$. fluorescens Migula 1894. A definition of this species is suggested.

In spite of the common occurrence of pseudomonads and the large volume of literature on members of this group, their identification and classification is not easy. The potential animal pathogen Pseudomonas aeruginosa has been most studied and many now believe that this species, whether forming pyocyanine or not, may be fairly easily distinguished (Haynes, 1951; Gaby \& Free, 1953; Gaby, 1955; Gaby \& Hadley, 1957). Similarly, increasing knowledge of other economically important pseudomonads, i.e. the phytopathogens, is facilitating their characterization and resulting in more satisfactory identification and classification of a reduced number of species (Elliott, 1951; Dowson, 1957). 
However, many studies of the more ecologically specialized pseudomonads seem to have been hampered by the lack of a detailed characterization, by modern standardized methods, of the commonly occurring, saprophytic, (usually) fluorescent, pseudomonads. Model examples of such studies are those of St John-Brooks, Nain \& Rhodes (1925) and Clara (1934), who compared green-fluorescent phytopathogens and saprophytes. Clara gave a detailed description of his saprophytic Pseudomonas fuorescens (Flügge) Migula 1900, and commented that it would be interesting to know whether the specific characteristics applied to all other green-fluorescent saprophytes. Seleen \& Stark (1943) carefully investigated 199 isolates of non-specialized fluorescent pseudomonads and divided their collection into 14 groups on the basis of various physiological characters. Their $\boldsymbol{P}$. aeruginosa group was distinctive, but they admitted that the separation of the other groups was often arbitrary or based on slight differences. They did not find any group which conformed with the description of $\boldsymbol{P}$. fluorescens in Bergey's Manual (presumably the 5th ed., 1939). The description of $\boldsymbol{P}$. fluorescens given in the 7 th edition (1957) of Bergey's Manual has not been revised as compared with that in the 6 th edition (1948), and many other soil- and water-inhabiting species are still poorly characterized. In some cases the differentiating criteria are unstable, e.g. pigment production and the reactions of cultures in milk or gelatin media (Rhodes, 1957). The use of the terms 'Pseudomonas sp.' or 'Pseudomonas fluorescens species-group' (the latter term introduced by Stanier, 1947, but nowhere defined in detail) is another indication of the need for more precise descriptions and definitions. The results of a study of 169 pseudomonad isolates over a period of seven years, by a wide range of old and new criteria are now presented.

\section{METHODS}

Samples of natural waters, soil, sewage, milk, diseased plants, contaminated human blood, etc. were streaked on yeast extract + peptone agar (YE agar) of the following composition $(\% \mathrm{w} / \mathrm{v})$ : Oxoid bacteriological yeast extract, 0.3; peptone (Evans), 1.0; $\mathrm{NaCl}, \mathbf{0 . 5}$; agar, 2.0 ; adjusted to $\mathrm{pH} \mathrm{7.2-7 \cdot 4}$ with $\mathrm{NaOH}$. After incubation for 3 days at $25^{\circ}$ colonies which were surrounded by the characteristic green-yellow water-soluble fluorescin were picked off into yeast extract broth (YE broth; i.e. the above medium minus agar). Altogether 145 single-colony isolates were purified by alternate subcultivation of single colonies into YE broth and streaking on YE agar, the two processes being repeated at least five times. Nineteen cultures of phytopathogenic $\boldsymbol{P}$ seudomonas spp. were kindly supplied by Dr W. J. Dowson (Cambridge) and 5 named cultures were obtained from the National Collection of Type Cultures, (NCTC). Table 1 gives details of the isolates used.

The purified isolates were then preserved as $24 \mathrm{hr}$. cultures (except in the case of five slowly growing phytopathogens which required $48 \mathrm{hr}$. incubation) on YE agar slopes covered completely with mineral oil (Rhodes, 1957). For the cytological, cultural and biochemical investigations now to be described, a standard inoculum consisting of one $4 \mathrm{~mm}$. loopful of a $24 \mathrm{hr}$. YE broth $(48 \mathrm{hr}$. 


\section{Table 1. Sources of Pseudomonas isolates}

\begin{tabular}{|c|c|c|c|}
\hline $\begin{array}{l}\text { Isolate } \\
\text { number }\end{array}$ & $\begin{array}{l}\text { Source and date of } \\
\text { isolation (in parentheses) }\end{array}$ & $\begin{array}{l}\text { Isolate } \\
\text { number }\end{array}$ & $\begin{array}{l}\text { Source and date of isolation } \\
\text { or receipt (in parentheses) }\end{array}$ \\
\hline 3 & $\begin{array}{l}\text { Freshwater algal tank, Botany } \\
\text { Dept., Reading University }\end{array}$ & 34 & $\begin{array}{l}\text { Rotting cucumber, Reading } \\
\text { (20. vi. 51) }\end{array}$ \\
\hline $4 / 2,4 / 3$ & $\begin{array}{l}\text { (12. iii. 51) } \\
\text { Puddle, N.I.R.D. Shinfield, }\end{array}$ & $35 / 1$ to $35 / 3$ & $\begin{array}{l}\text { Pond, Mapledurham, Reading } \\
\text { (9. vii. 51) }\end{array}$ \\
\hline $\mathbf{5} / \mathbf{1}, \mathbf{5} / \mathbf{2}, \mathbf{5} / \mathbf{3}$ & $\begin{array}{l}\text { Reading (12. iii. 51) } \\
\text { Ornamental garden pond, Warwick }\end{array}$ & $36 / 1$ to $36 / 4$ & $\begin{array}{l}\text { Pond, Forbury Gardens, Reading } \\
\text { (9. vii. 51) }\end{array}$ \\
\hline $\begin{array}{l}5 / 4,5 / 5,5 / 8 \\
7 / 3,7 / 6\end{array}$ & & 38 & $\begin{array}{l}\text { Stream, Pinge Wood, Reading } \\
\text { (17. vii. 51) }\end{array}$ \\
\hline & (17. iii. 51) & 39 & Stream (2), Pinge Wood, Reading \\
\hline $8 / 1$ to $8 / 16$ & $\begin{array}{l}\text { Contaminated human serum, } \\
\text { Lister Institute, Elstree } \\
\text { (3. iv. 51) }\end{array}$ & $40 / 1$ to $40 / 3$ & $\begin{array}{l}\text { (17. vii. 51) } \\
\text { Pond, Pinge Wood, Reading } \\
\text { (17. vii. 51) }\end{array}$ \\
\hline $9 / 1$ to $9 / 4$ & $\begin{array}{l}\text { Large ornamental garden pond, } \\
\text { Warwick Road, Reading }\end{array}$ & 41 & $\begin{array}{l}\text { Gravel pit, Burghfield, Reading } \\
\text { (17. vii. 51 }\end{array}$ \\
\hline $10 / 1,10 / 3$ & Freshwater mollusc tank, Zoology & $042 / 3$ & $\begin{array}{l}\text { River Loddon, Reading } \\
\text { (17. vii. 51) }\end{array}$ \\
\hline $10 / 4$ & $\begin{array}{l}\text { Dept., Reading University } \\
\text { (11.iv. 51) }\end{array}$ & $43 / 1$ to $43 / 4$ & $\begin{array}{l}\text { Ditch, N.I.R.D. Reading } \\
\text { (27. v. 51) }\end{array}$ \\
\hline $\begin{array}{l}12 / 1,12 / 3 \text { to } \\
12 / 6\end{array}$ & $\begin{array}{l}\text { Flooded meadow, Whiteknights } \\
\text { Park, Reading (11. iv. 51) }\end{array}$ & 45 & $\begin{array}{l}\text { Tap water from vase containing } \\
\text { Lathyrum odoratum (25. vii. 51) }\end{array}$ \\
\hline $13 / 1$ to $13 / 4$ & $\begin{array}{l}\text { Pond, Shinfield Road, Reading } \\
\text { (11. iv. 51) }\end{array}$ & Amis & rrot, Reading \\
\hline $14 / 1,14 / 2$ & $\begin{array}{l}\text { Ditch, Shinfield Road, Reading } \\
\text { (11. iv. 51) }\end{array}$ & $47 / 1$ to $47 / 5$ & $\begin{array}{l}\text { from vase containing } \\
n \text { sp. }(1 . x .51)\end{array}$ \\
\hline $\begin{array}{l}15 / 1,15 / 3 \text { to } \\
15 / 6\end{array}$ & $\begin{array}{l}\text { Pond, Whitley Wood Lane, } \\
\text { Reading (11.iv. 51) }\end{array}$ & 49 & $\begin{array}{l}\text { Soil, Microbiology Dept. garden, } \\
\text { Reading (3. xi. 51) }\end{array}$ \\
\hline $16 / 1,16 / 2$ & $\begin{array}{l}\text { Ditch, Whitley Wood Lane, } \\
\text { Reading (11.iv. 51) }\end{array}$ & $\mathbf{5 0}$ & $\begin{array}{l}\text { Tap water containing Ilex sp. and } \\
\text { Artemis } \mathrm{sp.}(13 . \mathrm{xi} . \mathrm{51})\end{array}$ \\
\hline $18 / 1$ & $\begin{array}{l}\text { Brown spot lesions on Primula sp. } \\
\text { leaves; Warwick Road garden, } \\
\text { Reading (11. iv. 51) }\end{array}$ & 51 & $\begin{array}{l}\text { Aerial contaminant, Microbiology } \\
\text { Dept., Reading (15. xi. 51) } \\
\text { River Kennet, Reading (13. xi. 51) }\end{array}$ \\
\hline 19 & $\begin{array}{l}\text { Whiteknights Park Lake, Reading } \\
\text { (1949) }\end{array}$ & $\begin{array}{l}53 / 1,53 / 2 \\
54\end{array}$ & $\begin{array}{l}\text { Stream, Reading (14. xii. 51) } \\
\text { River Thames, Reading }\end{array}$ \\
\hline 20 & $\begin{array}{l}\text { Microbiology Dept. Stock culture } \\
\text { B17; (1949) }\end{array}$ & 55 & $\begin{array}{l}\text { (14. xii. 51) } \\
\text { Puddle, University grounds, }\end{array}$ \\
\hline 21 & $\begin{array}{l}\text { Septic appendix; Dr T. Richards } \\
\text { (1950) }\end{array}$ & & $\begin{array}{l}\text { Reading (14. xii. 51) } \\
\text { Soil inoculated into chemically }\end{array}$ \\
\hline $22 / 1$ to $22 / 7$ & $\begin{array}{l}\text { Raw TT milk, Reading } \\
\text { (27. iv. 51) }\end{array}$ & & $\begin{array}{l}\text { defined inositol medium } \\
\text { (14. xii. 51) }\end{array}$ \\
\hline $23 / 1,23 / 3$ & $\begin{array}{l}\text { Shot-holed lesions Ilex sp. leaves, } \\
\text { Reading University (1. v. 51) }\end{array}$ & d52 & $\begin{array}{l}\text { Dr W. J. Dowson (WJD) } \\
\text { P. medicaginis var. phaseolicola }\end{array}$ \\
\hline $24 / 1,24 / 2$ & $\begin{array}{l}\text { Calf faeces sample, Royal Veterin- } \\
\text { ary College (10. v. 51) }\end{array}$ & d53 & $\begin{array}{l}\text { (b52) (1. xi. 51) } \\
\text { WJD. P. viridiflava (53) (1. xi. 51) }\end{array}$ \\
\hline $25 / 1,25 / 2$ & $\begin{array}{l}\text { Aerial laboratory contaminant, } \\
\text { Royal Veterinary College } \\
(10 . v .51)\end{array}$ & $\begin{array}{l}d 64 \\
d 69 \\
d 72\end{array}$ & $\begin{array}{l}\text { WJD. P. savastanoi (64) (1. xi. 51) } \\
\text { WJD. P. tolaasii (9) (1. xi. 51) } \\
\text { WJD. P. delphini (72) (1. xi. 51) }\end{array}$ \\
\hline $26 / 1$ to $26 / 6$ & $\begin{array}{l}\text { Raw milk sample, Reading } \\
\text { (17. v. 51) }\end{array}$ & $\begin{array}{l}\text { d 73 } \\
\text { d } 133\end{array}$ & $\begin{array}{l}\text { WJD. P. mori (73) (1. xi. 51) } \\
\text { WJD. P. primuli (133) (1. xi. 51) }\end{array}$ \\
\hline $27 / 1$ to $27 / 7$ & $\begin{array}{l}\text { Filter-bed sludge, Reading town } \\
\text { waterworks (17, v. 51) }\end{array}$ & d 152 & $\begin{array}{l}\text { WJD. P. viridilivida (152) } \\
\text { (1. xi. 51) }\end{array}$ \\
\hline $28 / 3$ to $28 / 6$ & $\begin{array}{l}\text { Pre-filter tanks, Reading town } \\
\text { waterworks (17. v. 51) }\end{array}$ & $\begin{array}{l}\text { d 221 } \\
\text { d } 236\end{array}$ & $\begin{array}{l}\text { WJD. P. tabaci }(221)(1 . x i .51) \\
\text { WJD. P. lachrymans (236) }\end{array}$ \\
\hline 30 & River Kennet (25. v. 51) & & \\
\hline $31 / 1$ to $31 / 3$ & Rotting carrots, Reading (1. vi. 51) & d 244 & WJD. P. barkeri (244) (1. xi. 51) \\
\hline 32 & $\begin{array}{l}\text { Rotting cucumber, Reading; } \\
\text { (14. vi. 51) }\end{array}$ & $\mathrm{d} 248$ & $\begin{array}{l}\text { WJD. P. atrofaciens }(248) \\
\text { (1. xi. 51) }\end{array}$ \\
\hline
\end{tabular}




\begin{tabular}{|c|c|c|c|}
\hline \multicolumn{4}{|c|}{ Table 1 (cont.) } \\
\hline $\begin{array}{l}\text { Isolate } \\
\text { number }\end{array}$ & $\begin{array}{l}\text { Source and date of } \\
\text { isolation (in parentheses) }\end{array}$ & $\begin{array}{l}\text { Isolate } \\
\text { number }\end{array}$ & $\begin{array}{l}\text { Source and date of isolation } \\
\text { or receipt (in parentheses) }\end{array}$ \\
\hline d251 & WJD. P. cruciviae (251) (1. xi. 51) & $\mathbf{5 9 4 0}$ & NCTC. $P$. fluorescens (5940) \\
\hline d260 & WJD. P. aptata (260) (1. xi. 51) & & (1. xi. 51) \\
\hline d 263 & WJD. P. angulata (263) (1. xi. 51) & 7357 & NCTC. $P$. chlororaphis (7357) \\
\hline d270 & WJD. P. mors-prunorum (270) & & (1. xi. 51) \\
\hline & (1. xi. 51) & 7810 & NCTC. P. hydrophila (7810) \\
\hline d281 & WJD. P. syringae (281) (1. xi. 51) & & (5. iv. 53) \\
\hline d289 & WJD. P. marginalis (289) (1. xi. 51) & 8049 & NCTC. P. icthyosmia (8049) \\
\hline d 300 & WJD. P. pisi (300) (1. xi. 51) & & (5. iv. 53) \\
\hline 3246 & NCTC. $P$. syncyanea (3246) & KB 1 & $\begin{array}{l}\text { Dr M. Kogut, Sheffield strain 4/4, } \\
\text { Pseudomonas sp. (3. xii. 53) }\end{array}$ \\
\hline
\end{tabular}

culture for 5 phytopathogens) was always used. Stock 'bench broth' cultures were derived from the oil-preserved slope cultures at 6-monthly intervals, and these 'bench broths' were used to supply the $24 \mathrm{hr}$. YE broth inocula when necessary.

All cultures when being characterized were incubated aerobically at $25^{\circ}$ for 28 days unless otherwise stated, and detailed recordings were made after 1, 2, 3, $7,14,21$ and 28 days of incubation. In order to assess the stability of the various properties, each character was investigated at least 3 times during a period of at least 5 years.

\section{Cytological studies}

Morphology and Gram reaction. Air dried films of $24 \mathrm{hr}$. YE broth cultures were stained by the method of Gram as modified by Hucker (Manual of Methods, 1957, p. 16). Measurements of size were made by using a calibrated eye-piece graticule. Shape and size and the Gram reaction were also noted for organisms from $24 \mathrm{hr}$. YE agar cultures.

Nuclear staining reaction. Wet films of young (6-8 hr.) YE agar cultures, of 10 isolates only, were fixed in $\mathrm{OsO}_{4}$ vapour for 1-2 min., hydrolysed in $\mathrm{N}-\mathrm{HCl}$ for various lengths of time (5-15 min.), stained with dilute Giemsa solution (Gurr's Michrome) at $37^{\circ}$ for $30 \mathrm{~min}$. and examined microscopically as wet mounts in dilute Giemsa solution under a coverslip.

Flagella staining. Three methods were investigated. The first was the modification of Morton's Night Blue method as described by Dowson (1949, p. 57), the second used a similar mordant (tannic acid + potash alum) but the dye was basic fuchsin (Leifson, 1951); the third method, which was found to be best, was a modification of Fontana's silver-plating technique (Rhodes, 1958).

Slime and capsule formation. Abundant slime and capsule formation was a striking feature seen in many of the silver-plated preparations made from $24 \mathrm{hr}$. YE agar cultures and stained to show flagella. Therefore methods recommended for the demonstration of capsules and exocellular slime (Klieneberger-Nobel, 1948, 1950; Novelli, 1953: methods of Leifson (p. 27) and of Anthony (p. 29), Manual of Microbiological Methods, 1957). From preliminary experiments it was apparent that the age of the culture was of the utmost importance, because obvious macroscopical mucoidness often appeared, 
disappeared and then reappeared on ageing. Therefore incubation for 7 days at $\mathbf{2 5}^{\circ}$ was chosen as the standard age of culture for cytological examination; to standardize conditions still further, 7-day cultures in Koser's citrate medium (Koser, 1923) were also examined for slime and capsule production by Novelli's Alcian Blue staining method and by the silver-plating method.

\section{Growth characters}

(1) Growth with complex nutrient media

The appearance of growth in YE broth, used throughout for rapid propagation of pseudomonads, differed with individual isolates. When YE agar was used for the preparation of shake, slope and streak-plate cultures, there were some differences between strains.

(a) Anaerobic growth. YE broth $+1.0 \%(\mathrm{w} / \mathrm{v})$ glucose cultures were incubated for 7 days in a McIntosh and Fildes's jar containing a mixture of $95 \%(\mathrm{v} / \mathrm{v}) \mathrm{H}_{2}+5 \%(\mathrm{v} / \mathrm{v}) \mathrm{CO}_{2}$. (See also section on nitrate utilization.)

(b) Effect of temperature. The ability of isolates to grow at $5^{\circ}, 12-15^{\circ}, 2^{\circ}$, $30^{\circ}, 37^{\circ}$ and $42^{\circ}$ (in water baths; $\pm 0.5^{\circ}$ ) in $5 \mathrm{ml}$. YE broth was examined.

(c) Effect of the initial $\mathrm{pH}$ value of the medium. Five ml. volumes of $\mathrm{YE}$ broth were adjusted to $\mathrm{pH} 7 \cdot 0,6 \cdot 0,5 \cdot 5,5 \cdot 0,4 \cdot 5$ and $4 \cdot 0$ with $\mathrm{N}-\mathrm{HCl}$ and used for growth tests in the usual way.

(d) Effect of $\mathrm{NaCl}$ concentration. Five ml. volumes of $\mathrm{YE}$ broth containing $6 \cdot 5,5 \cdot 0$ and $3 \cdot 0(\%, w / v) ~ N a C l$ were inoculated and incubated.

(e) Effect of bile salt. The effect of $0.5 \%(\mathrm{w} / \mathrm{v})$ sodium taurocholate (B.P.C. Evans) on the growth of isolates in $5 \mathrm{ml}$. YE broth was recorded.

(f) Resistance to the pteridine derivative 0/129. Shewan, Hodgkiss \& Liston (1954) recommended the use of the vibriostatic compound O/129 (2:4-diamino6:7-di-isopropylpteridine) to differentiate VibriofromPseudomonas, particularly the non-chromogenic pseudomonads. The compound (kindly supplied by Dr H. O. J. Collier) was tested by placing filter-paper strips soaked in a saturated aqueous solution of compound $0 / 129$ (sterilized by filtration through a sintered-glass filter) across streak inocula of the individual isolates on YE agar plates. Five Vibrio spp. cultures (from NCTC) and one V. icthyodermis kindly given by $\mathrm{Mr}$ Hodgkiss were used as controls.

(g) Growth on potato slopes. Potato slopes prepared according to the method described by Mackie \& McCartney (1953) were inoculated and incubated.

(2) Growth with chemically defined media

(a) Groroth in Koser's citrate medium. The ability of all isolates to grow in $5 \mathrm{ml}$. Koser's citrate medium (Koser, 1923) from a straight-wire inoculum of a $24 \mathrm{hr}$. YE broth culture was tested. Falsely positive results were detected by a straight-wire subculture into a second tube of Koser's medium from all the primary cultures which showed growth; further serial subcultures were carried out when necessary.

(b) Utilization of other organic acids as sole added carbon sources. Since all except 3 isolates grew well in Koser's citrate medium this suggested that ammonium-N was a suitable source of nitrogen for the growth of pseudo- 
monads (cf. Clara, 1934; Seleen \& Stark, 1948). Therefore the basal ammonium +inorganic salts medium of Koser, and also the basal ammonium + inorganic salts medium recommended by Dowson (1949), were used to investigate the utilization of the following organic acids as carbon source added to the basal medium without citrate at the indicated concentrations $(\%, \mathrm{w} / \mathrm{v}) ; \mathrm{Na}$ formate, 0.1 ; $\mathrm{Na}$ acetate, 0.2 ; lactic acid, 1.0 ; oxalic acid, $0.1 ; \mathrm{Na}$ succinate, 1.0 ; l-malic acid, 1.0, tartaric acid, $1 \cdot 0$; citric acid, 1.0. These media were adjusted to $\mathrm{pH} 7 \cdot 0-7 \cdot 2$ with $\mathrm{NaOH} ; 5 \mathrm{ml}$. volumes were sterilized by autoclaving (10 lb./sq. in. for $10 \mathrm{~min}$.). Inoculations were made with a straight wire from $24 \mathrm{hr}$. YE broth cultures. Subcultures were made when necessary.

(c) Utilization of carbohydrates as sole added carbon sources. The utilization of the following compounds was investigated: D-glucose, D-galactose, D-fructose, D-arabinose, L-arabinose, D-xylose, L-rhamnose, sucrose, maltose, lactose, trehalose, cellobiose, raffinose, dextrin, starch, cellulose (Whatman's no. 1 filter-paper strips), inulin, salicin, aesculin, sorbitol, mannitol, dulcitol, inositol. In general these carbon substrates were incorporated at $1.0 \%(w / v)$ in Dowson's (1949) ammonium + inorganic salts basal medium. Bromocresol purple ( $1 \mathrm{ml}$. of a $1.6 \%(\mathrm{w} / \mathrm{v})$ ethanolic solution/l. medium) was added as an indicator. Five ml. volumes of the media were at first sterilized by steaming for $1 \mathrm{hr}$. on each of 3 successive days; later it was sometimes found necessary to add the separately sterilized sugar solutions to the sterile basal medium because of the formation of toxic products when the complete medium was heat sterilized. The standard inoculum of one $4 \mathrm{~mm}$. loopful was retained because it had been shown that the use of this larger inoculum (as compared with the straight wire inoculum) did not give rise to falsely positive results. Control basal media not containing an added carbon source were also inoculated. The development of turbidity, acidity and gas was recorded.

Note $\mathrm{i}$. The aesculin medium did not contain acid indicator, and the cultures were tested for the presence of the aglycone aesculetin after incubation for 14 days; on adding 2 drops of $5.0 \%(\mathrm{w} / \mathrm{v}) \mathrm{FeCl}_{3}$ the cultures turned densely black when aesculetin was present. This test was not fully satisfactory because a few isolates grew slightly in the medium and the aesculetin test was doubtfully positive. Therefore Sneath's (1956 $a$ ) recommended methods involving the use of peptone + aesculin agar or broth and the microtest of Cowan (1953) were used to confirm aesculin hydrolysis.

Note ii. The growth test above was considered to be suitable for the detection of starch utilization, but diastatic activity was also investigated by more traditional methods. Streak cultures were prepared on $\mathbf{1} \cdot \mathbf{0}, \mathbf{0 . 5}$ and $\mathbf{0 . 1}$ $\%$, (w/v) starch + YE agar, and the plates flooded with Gram's iodine solution after incubation for 7 days.

(d) Aerobic versus anaerobic glucose utilization. Ten $\mathrm{ml}$. volumes of the basal peptone agar recommended by Hugh \& Leifson (1953) were used; glucose solution sterilized by filtration (sintered-glass) was added to make $1.0 \%(\mathrm{w} / \mathrm{v})$. Stab inoculations were made in duplicate cultures. One set of cultures was incubated in the usual way and the duplicates were sealed with a $1 \mathrm{~cm}$. layer of paraffin wax + a $1 \mathrm{~cm}$. layer of mineral oil before incubation. 
(e) Gluconate test. The defined medium of Koser (1923), but with the citric acid replaced by $0.5 \%(\mathrm{w} / \mathrm{v})$ gluconic acid and neutralized with $\mathrm{KOH}$, was used. Five ml. volumes were inoculated, and after incubation for 7 days $1 \mathrm{ml}$. Benedict's qualitative reagent for glucose was added. Then, after standing $10 \mathrm{~min}$. at room temperature, the cultures were heated at $100^{\circ}$ for $10 \mathrm{~min}$., and examined for reduction (Sneath, 1956a).

$(f)$ Voges-Proskauer $(V-P)$ and methyl red $(M R)$ tests. Fouad \& Richards (1953) recommended a glucose + ammonium + inorganic salts medium for examining the V-P and MR reactions by members of the Enterobacteriaceae; $7 \mathrm{ml}$. volumes of this medium were used here. The V-P and MR tests were carried out on $1 \mathrm{ml}$. samples of the cultures after 5 and 7 days of incubation. The O'Meara (1931) method of testing for acetoin was used.

(g) Utilization of miscellaneous carbon compounds. The following compounds were tested for their ability to support growth when added as carbon sources to the basal medium of Dowson $(1949 ; \%, w / v)$ : ethanol, 0.5 ; glycerol, 1.0 ; phenol, $0.1 ; m$-cresol, 0.1 ; naphthalene was used as whole medium saturated with solid recrystallized naphthalene. Five ml. volumes of medium were used for the growth test.

(h) Utilization of ammonium-N. (See Koser's citrate test, (a), above). Dowson's (1949) basal medium $+1 \cdot 0 \%(\mathrm{w} / \mathrm{v})$ glucose, galactose or citrate was also used. For every isolate a control tube of basal medium not containing added $\mathrm{N}$-source $\left(\mathrm{KH}_{2} \mathrm{PO}_{4}\right.$ replacing $\left.\mathrm{NH}_{4} \mathrm{H}_{2} \mathrm{PO}_{4}\right)$ was similarly inoculated and incubated.

(i) Utilization of nitrate- $N$. The ability of nitrate-N to support growth was investigated by using the following medium $(\%, w / v) ; \mathrm{K}_{2} \mathrm{HPO}_{4}, 0 \cdot 1 ; \mathrm{KCl}, 0.02$; $\mathrm{MgSO}_{4} \cdot \mathbf{7 H}_{2} \mathrm{O}, \mathbf{0} \cdot 02 ; \mathrm{KNO}_{3}, \mathbf{0} \cdot 1$; galactose, $1 \cdot 0$; adjusted to $\mathrm{pH} \mathbf{7} \cdot 0$ with $\mathrm{N}-\mathrm{NaOH}$. Duplicate cultures were incubated both aerobically and anaerobically for 7 days, and then examined for growth, for nitrite (Griess-Ilosvay reagents), for ammonia (Nessler's reagent) and visible gaseous products (accumulated in a Durham tube). All negative nitrite tests were checked for the presence of residual nitrate by the zinc dust method (ZoBell, 1932). Any reduction of nitrate after 7 days of aerobic incubation in conventional $0 \cdot 1 \%$ $(\mathrm{w} / \mathrm{v}) \mathrm{KNO}_{3}+$ peptone water medium was also similarly investigated in order to compare the properties of the organisms in the present collection with published descriptions of named pseudomonads. Microtests for the detection of nitrate-reducing ability by heavy suspensions were made by the method recommended by Brough (1950).

(j) Utilization of nitrite-N. Four methods were used. (1) Tests for growth and nitrite disappearance were made with the same glucose + inorganic salts basal medium as above but with the $\mathrm{KNO}_{3}$ replaced by $\mathrm{NaNO}_{2}$. Because of the possible toxicity of nitrite, three concentrations $(0.1,0.05,0.01, \%, w / v)$, were used. After 7 days of incubation nitrite was tested for by means of the Griess-Ilosvay reagents. (2) Koser's citrate medium $+0 \cdot 0005 \%(w / v) \mathrm{NaNO}_{2}$ was similarly used for growth and nitrite-disappearance tests. (3) Cultures in YE broth $+0.0005 \%(\mathrm{w} / \mathrm{v}) \mathrm{NaNO}_{2}+\mathbf{0 . 2 5} \%(\mathrm{w} / \mathrm{v})$ agar were also tested for nitrite disappearance after 1 and 5 days of incubation (Sneath, 1956a). 
(4) The Brough (1950) micromethod was adapted for testing for the disappearance of nitrite after incubating heavy suspensions in YE broth $+\mathbf{0 . 0 0 5} \%$ $(\mathrm{w} / \mathrm{v}) \mathrm{NaNO}_{2}$.

(k) Utilization of urea. Christensen's (1946) urea + peptone agar method was used to detect urea-decomposing isolates; this medium was not entirely suitable for pseudomonads because of simultaneous alkali formation from the peptone. Therefore a chemically defined medium with $2 \cdot 0 \%(\mathrm{w} / \mathrm{v})$ urea (Seitz-filtered) as sole added nitrogen source was also used; the basal medium contained phenol red and it was essentially that of Dowson (1949) except that the carbon source (galactose) was at $0 \cdot 1 \%(\mathrm{w} / \mathrm{v})$, to prevent acid production masking or inhibiting the urease action.

\section{Biochemical tests}

(a) Catalase production. A loopful of solid growth taken from a $24 \mathrm{hr}$. YE agar slope was removed into a drop of ' 10 vol.' hydrogen peroxide solution and examined for the production of gas bubbles.

(b) Ammonia production from peptone. Peptone water (YE broth minus yeast extract) in $5 \mathrm{ml}$. volumes was used. After incubation for 7 days the $\mathrm{pH}$ value of each culture was measured electrometrically, and ammonia was tested for by adding 2 drops of Nessler's reagent.

(c) Haemolysis. Streak cultures on $5 \%(\mathrm{v} / \mathrm{v})$ horse blood YE agar plates were examined for haemolysed zones.

(d) Reaction on egg-yolk medium. The appearance of the isolates when grown as surface streaks on egg-yolk plates (Knight \& Proom, 1950) was recorded.

(e) Gelatin hydrolysis. Stab inoculations into nutrient gelatin (YE broth + $12.0 \%, w / v$, Oxoid gelatin) were made. Cultures were incubated at $22^{\circ}$ and examined at intervals, the shape and approximate amount of liquefaction, when present, being noted. The possibility that the peptone might be preferentially used was considered, and so a similar medium without peptone was used for comparison. The streak plate method of Frazier (1926) for detecting gelatin hydrolysis was also used, and the width of the hydrolysed zone was measured after 7 days of incubation.

( $f$ ) Liquefaction of pectate gel. The method recommended by Dowson (1949) was used. Stab inoculations were made into a gel of calcium pectate, prepared by layering a solution of sodium pectate (A.S.P. Chemical Co. Ltd.) over calcium chloride agar. Cultures were examined for growth and liquefaction.

(g) Action on milk. Seven-ml. volumes of litmus milk and of methylene-blue milk (methylene blue, 1/20,000) were inoculated and examined for colour changes, clotting, casein digestion and dye reduction. Because of the difficulty of detecting milk-protein digestion in strongly alkaline liquid cultures, the method involving spot inoculation of cultures on to skim-milk agar plates (skim milk, $20 \%(\mathrm{v} / \mathrm{v})$; washed agar, $2 \cdot 0 \%(\mathrm{w} / \mathrm{v})$; adjusted to $\mathrm{pH} \mathbf{7 \cdot 2}$ ) was also used. After 7 days of incubation the plates were flooded with $\mathrm{HgCl}_{2}$ solution (Frazier, 1926), and any clear zones of hydrolysis measured.

(h) Indole production. Five ml. volumes of peptone (Evans) water cultures were incubated for 7 days, and then shaken with $1 \mathrm{ml}$. ether to extract indole 
which was detected by means of Ehrlich's reagents. The oxalic acid test paper method was used with Pseudomonas aeruginosa (to test for false positive results due to conversion of pyocyanine to its red salt in acid solution; Sandiford, 1987). Ability to produce indole from tryptophan was similarly investigated by using the Dowson (1949) galactose + ammonium + inorganic salts medium + $0.01 \%(w / v)$ tryptophan.

(i) Production of hydrogen sulphide. All isolates were first tested for their ability to produce $\mathrm{H}_{2} \mathrm{~S}$ from Kligler's iron agar (Oxoid) medium. A few isolates gave a positive reaction; the $\mathrm{H}_{2} \mathrm{~S}$ might have arisen from $\mathrm{S}$-containing amino acids or sodium thiosulphate in the medium, or from both. Therefore two chemically defined media were devised, one with cystine $(0.01 \%, \mathrm{w} / \mathrm{v})$ added to the Dowson-type ammonium + galactose+inorganic salts medium, the other with $1.0 \%(w / v)$ sodium thiosulphate added to the same basal medium. $\mathrm{H}_{2} \mathrm{~S}$ was detected by sterile lead acetate papers held in place by the cottonwool plugs of the cultures. After 7 days of incubation the cultures were also tested for dissolved sulphides by the addition of lead acetate solution. Because some results were inconclusive, a microtest was also used; heavy suspensions of organisms grown on YE agar for $24 \mathrm{hr}$. were suspended in $1 \mathrm{ml}$. of each of the two chemically defined media and incubated at $37^{\circ}$ for $24 \mathrm{hr}$. with lead acetate papers held in place by cotton-wool plugs. No carbon source was added to the thiosulphate-containing suspending medium because of the report by Leathen \& Braley (1955) of the chemical decomposition of thiosulphate to sulphate, hydrogen sulphide and sulphur at acid $\mathrm{pH}$ values.

(j) Hydrolysis of tributyrin. A stable emulsion of $1.0 \%(\mathrm{v} / \mathrm{v})$ tributyrin in YE agar was prepared by blending in a hand emulsifier; streak cultures were made on poured plates of this medium. Clear zones of hydrolysis were measured after different incubation periods.

(k) Hydrolysis of olive oil. Because the triglycerides of olive oil are composed of higher molecular-weight fatty acids than is tributyrin it was thought that this might affect the ease with which they were hydrolysed by pseudomonad enzymes. To encourage potential ability to hydrolyse olive oil, this was incorporated as the major added carbon source in the following medium $(\%, w / v)$ : $\mathrm{NH}_{4} \mathrm{H}_{2} \mathrm{PO}_{4}, 0 \cdot 1 ; \mathrm{KCl}, 0.02 ; \mathrm{MgSO}_{4} .7 \mathrm{H}_{2} \mathrm{O}, 0.02$; yeast extract (Oxoid), 0.3 ; agar, $2 \cdot 0$; olive oil, $5 \cdot 0$ : adjusted to $\mathrm{pH} 7 \cdot 8$ with $\mathrm{NaOH}$. The olive oil contained the base of Night Blue to a final concentration in the medium of $1 / 15,000$. This method was adapted from that of Jones \& Richards (1952). Streak plate cultures were examined for growth and the production of a blue salt (formed by the reaction of the liberated fatty acids with the weak base of the dye). Controls of all isolates were grown on plates of similar medium but without olive oil.

(l) Hydrolysis of margarine. The test method was similar to that of $(k)$ and again depended upon staining the margarine with the base of Night Blue and then incorporating $5.0 \%(\mathrm{v} / \mathrm{v})$ of it into YE agar.

$(m)$ Hydrolysis of Tween 80. The use of the water-soluble Tweens for easy detection of lipolytic activity by micro-organisms including $\boldsymbol{P}$ seudomonas aeruginosa was described by Sierra $(1957 a)$. His technique, using $1.0 \%(v / v)$ Tween 80 (polyoxyethylene sorbitan mono-oleate) in calcium chloride+ 
peptone agar, was adopted; parallel cultures on tributyrin + YE agar were simultaneously inoculated. After incubation the Tween cultures were examined for the presence of opaque haloes, due to the formation of conspicuous precipitates of calcium oleate round the zones of growth.

\section{RESULTS}

Morphology and Gram reaction. When YE broth and YE agar cultures (aged 18-24 $\mathrm{hr}$.) were examined by the Gram method, only Gram-negative rods were found. The usual width was $0.5-0.6 \mu$; a width of $0.7 \mu$ was recorded for 15 isolates. Average cell length was 1.5-2.0 $\mu$; with a range from $1 \cdot 0-3 \cdot 0 \mu$. With increasing age a greater proportion of the rods were of maximum length, but old cultures (14 days) showed only Gram-negative granules and debris. A few peculiarities were: (i) in some preparations all the rods were only faintly stained (controls on the same slides were normal); (ii) the arrangement of the rods was usually random from broth cultures, but from agar cultures the rods were often arranged in a reticulum; this mesh-work was fine or coarse, and the appearance suggested that a slime was holding the rods together, although no such material was demonstrable by the Gram method; (iii) other rod arrangements noted were, longitudinal pairs, short or long chains of rods, long filaments (apparently acellular). All these minor variations were not constant for a given isolate except for chain formation by three isolates, a faint Gramnegative reaction by two isolates and filament formation by four isolates.

Nuclear staining reaction. In spite of many attempts with different periods of hydrolysis and staining, and with cultures of different ages, very few convincing appearances of chromatinic bodies were obtained, although distinct positively stained bodies were visible in Bacillus cereus and Oidium lactis controls. In $12 \mathrm{hr}$. cultures of 7 isolates, small rods with one or two subpolar granules/rod, and longer rods with more granules, were seen. It is felt that the main difficulty is an optical one because of the small size of the rods.

Flagella staining. When young YE broth cultures were examined as hangingdrops, rapid motility was usually obvious. Of the flagella-staining methods tried, the silver-plating technique (Rhodes, 1958) was found to be superior in every way. Rhodes (1958) did not find any non-flagellate isolate of Pseudomonas, nor was any loss of flagella during maintenance of stock cultures on laboratory media seen; the number of flagella/rod, amphitrichy, and degree of flagellar curvature were found to be variable characters of little value for strain identification. For every isolate polar flagella were demonstrated, 1-3 flagella/rod being characteristic of Pseudomonas, but numbers up to 10 were common.

Slime and capsule formation. Abundant slime formation was a feature of many preparations stained by the silver-plating method to show fiagella (Rhodes, 1958). The amount of exocellular slime varied from abundant to very slight, but it was rare for a pseudomonad not to produce any slime, whatever the age of the culture (12 hr.-28 days). The results of Alcian Blue staining and the silver-plating method were in good agreement. Klieneberger- 
Nobel's (1950) staining method for detecting exocellular slime was followed using 7-day YE broth and Koser's citrate medium cultures; the results were not similar (quantitatively or qualitatively) in the two media; but only five isolates showed complete absence of slime. Considerable exocellular slime production was characteristic for 164 of 169 Pseudomonas isolates investigated. (See Eagon, 1956, for conditions affecting slime production by $\boldsymbol{P}$. fluorescens; Fuchs, 1956, concerning levan synthesis from sucrose by three strains of nonphytopathogenic $\boldsymbol{P}$. fluorescens.)

In some isolates distinct capsules were apparent round a few organisms in a preparation, but this character did not appear to be constant or stable because even in one microscope field some rods were capsulated while others were not. Usually the capsules were not conspicuous; the typical width was $0 \cdot 4 \mu$ or less. Table 2 shows that both the medium in which the organism was grown and the age of the culture influenced capsule formation. This cytological character appears to be of little use for diagnostic purposes.

Table 2. Influence of medium and age of cultures on capsulation in 169 isolates of Pseudomonas

Each isolate was examined by the Alcian Blue staining method (Novelli, 1953) and the silver-plating method (Rhodes, 1958).

\author{
Cultural conditions \\ 1 day on yeast-extract agar \\ 7 days in yeast-extract broth \\ 7 days in Koser's citrate medium
}

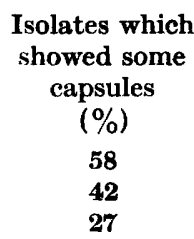

42

27

\section{Growth characters}

(1) Growth with complex media

It is not possible to describe here the cultural characters of all isolates when they were grown in YE broth or on YE agar slopes, in stabs, shakes or surface streak-plate cultures. Only the usual characteristics of the growth in each type of culture are given below. The observations were made after inoculation with a standardized inoculum from a $24 \mathrm{hr}$. culture on YE broth, during incubation for 28 days at $25^{\circ}$.

$Y E$ broth. At 1 day: slight-moderate homogeneous turbidity. No deposit. No pellicle. No pigment. No odour. Slight frothing of medium on shaking.

At 2 days : moderate-dense turbidity. Slight easily dispersed white deposit. Thin pellicle and ring. Slight green fluorescent pigment, more noticeable at the surface. Slight sweet fishy odour. Slight frothing and a characteristic cloudy, swirling effect on shaking, becoming homogeneous but for broken pellicle.

At 3 days as after 2 days but pigment more intense.

At 7 days: slight turbidity. Much whitish deposit, seen to be composed of slimy strands or a dense slimy mass on shaking. Thin pellicle (white). Marked white ring. Green-yellow soluble pigment of maximum intensity. Strong mawkish sweet fishy odour. Considerable frothing of medium on shaking. 
At 14 days : as at 7 days but turbidity very slight and slimy deposit abundant. More marked frothing on shaking. Pigmentation more yellow-orange; $\mathrm{pH}$ value $8 \cdot 3-8 \cdot 7$.

At 21 days: no further change.

At 28 days: slight turbidity. Abundant mass of slimy whitish growth at base of tube. Medium orange-brown. Viable.

$Y E$ agar slope. At 1 day: thin, spreading, cream-white growth. Transparent by transmitted light. Smooth, or slightly 'beaten metal' surface. Edge entire or crenate. Slight sweet fishy odour. Moderate amount of green-yellow fluorescent pigment in the medium. Butyrous consistency. Easily emulsifiable with water forming a homogeneous white suspension.

At 2 days : good growth, slightly thicker but still transparent by transmitted light. Pigment more pronounced. Marked fishy odour.

At 3 days: no further changes.

At 7 days: as at 2 days but more marked 'beaten metal' surface. Greenyellow pigmentation of medium maximal. Very slight odour. Translucent by transmitted light. Edge slightly crenate. No further changes.

At 14 days: on subsequent incubation the only conspicuous change was a slow darkening of the medium from yellow $\rightarrow$ orange $\rightarrow$ brown, more marked indentation of the edge and increasing transparency of the growth as viewed by transmitted light.

At 28 days: still viable.

$Y E$ agar stab. At 1 day: cream colony on surface at point of inoculation. At 2 days : larger surface colony and faint growth along line of stab.

At 3 days: no further changes.

At $\boldsymbol{\gamma}$ days: cream surface colony spreading to periphery. Growth along line of stab thicker in upper region, but still slight. Very slight green pigmentation in upper $5 \mathrm{~mm}$. medium only.

At 14 days: no further changes on prolonged incubation.

At 28 days: still viable.

$Y E$ agar shake. At 1 day: slight film of whitish growth at surface only.

At 2 days: Moderate amount of white growth at surface only

At 3 days: no further changes.

At 7 days: thick film of cream-white surface growth only, with very slight production of green pigment in upper $5 \mathrm{~mm}$. medium only.

At 14 days: no further changes on prolonged incubation.

At 28 days: still viable.

Colony on $Y E$ agar. At 1 day; $0.5 \mathrm{~mm}$. diameter. White-cream coloured. Low convex. Surface smooth and shining. Transparent by transmitted light. Medium slightly coloured due to production of green-yellow fluorescent pigment. Butyrous consistency. Colony easily emulsified with water forming a homogeneous white suspension. Slight sweet fishy odour.

At 2 days: circular 1.5-2.0 mm. diameter. Cream-white colour. Low convex. Surface smooth and shining. Transparent by transmitted light. Edge entire. Moderate production of green-yellow water-soluble fluorescent pigment. 
Marked mawkish sweet fishy odour. Butyrous. Easily emulsified with water forming a homogeneous white suspension.

At 3 days: little further change.

At 7 days: circular, $\mathbf{4} \cdot 0-5 \cdot 0 \mathrm{~mm}$. diameter. Cream coloured. Flattened, or very low convex contour. Surface smooth and shining. Transparent or translucent by transmitted light. Edge entire. Maximum production of green-yellow water-soluble fluorescent pigment. Mawkish sweet fishy odour. Butyrous. Easily emulsified with water giving a homogeneous white suspension.

At 14 days: as at 7 days except for increased flattening, and the differentiation of an even, narrow, very thin flat margin $c .0 .5 \mathrm{~mm}$. wide; surface of 'beaten metal' appearance; pigments in medium turning more yellow-orange.

At 21 days: as at 14 days but differentiated margin more conspicuous; edge becoming crenate or irregularly lobed; transparent by transmitted light and medium pale brown.

At 28 days: approximately circular, cream fawn colour; 6.0-8.0 $\mathrm{mm}$. diameter. Moderately wide, very flat, thin margin with lobed or crenate outline. Whole colony very flat and transparent by transmitted light. Surface may be smooth, but usually 'beaten-metal', and shining. Medium pale brown. Butyrous consistency. Emulsion in water cream-white and homogeneous. Marked unpleasant mawkish sweet fishy odour. Organisms viable.

General comments. Individual isolates showed minor variations such as lack of pellicle formation, slight or intense pigmentation, dull or rough surface appearance and differences in opacity of the growth on solid media. Differences in the colonial appearance of streak-plate cultures were common. No full explanation of the various colonial types encountered is yet possible, although further investigations (cytological, physiological, biochemical) have been carried out. So far it has been found that even the most conspicuous colonial differences are only rarely correlated with any qualitative differences in the diagnostic criteria described in this report (contrast Williamson, 1956, who had colonial variants of Pseudomonas aeruginosa which showed differences in mouse virulence and carbohydrate utilization). Others, e.g. Suire (1958), have described the production of spontaneous colonial mutants or dissociants by Pseudomonas spp.

(a) Anaerobic growth. Only two isolates, 7810 (Pseudomonas hydrophila) and 8049 ( $P$. icthyosmia) grew under strictly anaerobic conditions in glucose YE broth; in this they grew equally well aerobically or anaerobically. The organisms in all cultures were still viable after anaerobic incubation for $\mathbf{7}$ days, but are regarded as obligate aerobes; this agrees with the views of Seleen \& Stark (1943).

(b) Effect of temperature. Most isolates grew well at all temperatures between $5^{\circ}$ and $30^{\circ}$ and, with few exceptions, there were no clear-cut temperature optima between $12^{\circ}$ and $30^{\circ}$, either on the basis of rate of growth or the final amount of it. Nine isolates only were able to grow well at $37^{\circ}$; these grew also at $42^{\circ}$. Only five isolates failed to grow at $5^{\circ}(20,21,24 / 1,24 / 2$ and $\mathrm{dr3})$, but all of these except $\mathrm{d} 73$ were able to grow at $42^{\circ}$. Thus the published opinions (Seleen \& Stark, 1943; Gaby, 1955) concerning temperature and Pseudomonas 
growth were confirmed; the only three known $P$. aeruginosa (pyocyanineproducing) isolates of the collection $(20,24 / 1,24 / 2)$ did grow at $42^{\circ}$; no pyocyanine was produced by any of these isolates at $12^{\circ}$ or $42^{\circ}$. Of the remaining six isolates which grew at $42^{\circ}, \mathrm{d} 73$ was a peritrichously-flagellate rod; 7810 and 8049 were known to be animal pathogens and facultatively anaerobic polar flagellates of the genus Aeromonas (Kluyver \& van Niel, 1936). Isolate 5940 was supplied from the NCTC as $P$. fluorescens; 21 was obtained from an inflamed human appendix; it is possible that these last two isolates were apyocyaninogenic strains of $\boldsymbol{P}$. aeruginosa. Isolate 55 seemed unique as a saprophytic pseudomonad able to grow at $42^{\circ}$, but in fact it was no longer typical, for it had early undergone a change to give a slow-growing organism not producing fluorescin and with an unusual pin-point colonial morphology. It is concluded that the growth temperature alone is of limited use for the identification of polarly-flagellate rods because of their normally wide temperature range; and the $42^{\circ}$ growth test must be interpreted in conjunction with other characters, as emphasized by Haynes (1951).

(c) Effect of the initial $\mathrm{pH}$ value of the medium. All isolates grew well in YE broth with an initial $\mathrm{pH}$ value of 7.0 or 6.0 , none grew at $\mathrm{pH} 4.5$ or 4.0 . Only isolates $\mathrm{d} 64$ and $\mathrm{d} 73$ failed to grow at $\mathrm{pH} \mathrm{5.5}$ and all except seven isolates

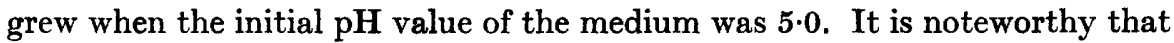
nearly all of the aberrant isolates were named phytopathogens.

(d) Effect of $\mathrm{NaCl}$ concentration. All isolates grew well in $\mathrm{YE}$ broth $+\mathbf{3} \cdot 0 \%$ (w/v) $\mathrm{NaCl}$; with isolate $\mathbf{d 7 2}$ (Pseudomonas delphini) only, was growth slow. In $5.0 \%(\mathrm{w} / \mathrm{v}) \mathrm{NaCl}$ medium growth of $151(89 \%)$ of the isolates was found, in contrast to the observations of Seleen \& Stark (1943) who found that very few pseudomonads grew in their chemically defined asparagine medium $+5.0 \%$ $(\mathrm{w} / \mathrm{v}) \mathrm{NaCl}$. In the $6.5 \% \mathrm{NaCl}+\mathrm{YE}$ broth rapid growth was uncommon but $32(18.9 \%)$ isolates grew after a lag period, often of 7-14 days duration; Seleen \& Stark obtained no growth in their $6.5 \% \mathrm{NaCl}$ medium. Typically in the $\mathrm{NaCl}+$ broth cultures a dense slimy mass accumulated at the base of the tube, leaving the supernatant fluid almost clear; other features were the absence of fluorescent pigment (all cultures) and relatively lower salt tolerance of many of the named phytopathogens examined.

(e) Effect of bile salt. Many isolates $(146 / 169 ; 86 \%$ ) grew well in the bile salt medium, but usually incubation for 3 days was necessary before definite turbidity was seen. Four phytopathogens did not grow in the medium and the remaining 19 isolates showed only sparse turbidity after incubation for $\mathbf{2 8}$ days. Isolate 7810 (Pseudomonas hydrophila) showed a slight acid reaction. An incidental observation of importance in water-testing was that $\boldsymbol{P}$. aeruginosa grew well on MacConkey agar at $37^{\circ}$.

(f) Resistance to the pteridine derivative $0 / 129$. This compound had no effect on the growth of any of the true Pseudomonas isolates (i.e. excluding the two Aeromonas spp.); unfortunately none of the five NCTC Vibrio spp. cultures were affected either. Isolate $\mathrm{d} 7 \mathrm{73}$, obtained as $\boldsymbol{P}$. mori but found to be a rod with peritrichous flagella, was the only susceptible organism found; in all tests at least a $4 \mathrm{~mm}$. zone of inhibition of growth was evident. Because of these 
unpromising results Dr H. O. J. Collier kindly supplied a sample of the more water-soluble phosphate derivative of $\mathrm{O} / 129$, and $\mathrm{Mr}$ Hodgkiss sent a sensitive culture of Vibrio icthyodermis PL 1 as a control culture for further experimentation. $V$. icthyodermis was sensitive to the original compound $0 / 129$ but a wider zone of inhibition was noted with the phosphate derivative $(15 \mathrm{~mm}$. zone compared with $10 \mathrm{~mm}$.); the NCTC $V$. alcaligenes also showed a $7 \mathrm{~mm}$. zone of inhibition. Of the Pseudomonas isolates, only 7810 and 8049 (the two Aeromonas isolates) were inhibited by the phosphate derivative; no growth was visible in a zone $5 \mathrm{~mm}$. wide. After a comparative investigation of the three sensitive isolates, $V$. icthyodermis PL1, $7810(P$. hydrophila) and 8049 (P. icthyosmia), I believe them to be very closely related; whether they are to be regarded as Vibrio or Aeromonas spp. is a side-issue here. It was concluded that polarly-flagellate, aerobic, oxidative pseudomonads were not inhibited by the vibriostatic pteridine derivatives tested.

(g) Growth on potato slopes. All isolates except d73 grew on potato slopes. Abundant growth, variously pigmented (cream, fawn, yellow, orange, black) was noted after 2-3 days. The medium was also usually pigmented; the potato tissue turned various shades of brown and fluorescin was produced by most of the cultures. Because different batches of potato gave rise to different types of growth and pigmentation, further details were not useful. No marked maceration of the potato was evident in any culture.

\section{(2) Growth with chemically-defined media}

(a) Growth in Koser's citrate medium. All isolates except 25/2, d73 and 7810 grew well in this medium. The three exceptions were anomalous in other respects; isolate $25 / 2$ resembled $X$ anthomonas in many growth and cultural characters; isolate $\mathrm{d} 73$ was peritrichously flagellate and isolate 7810 was an Aeromonas spp. Therefore this growth test appeared useful as a simple diagnostic criterion for a Pseudomonas sp., confirming the findings of Clara (1934), Seleen \& Stark (1943), Erikson (1945) and Naylor (1954). The mineral salt composition of this medium was obviously suitable for Pseudomonas growth.

(b) Utilization of other organic acids as sole added carbon sources. With the described test method, and either the Dowson-type or the Koser-type basal salts media there were four kinds of results: isolates which failed to grow; isolates which produced sparse turbidity after prolonged incubation which was not reproducible on subculture; isolates which slowly developed a sparse turbidity which was subculturable (at least three times); isolates which grew well and rapidly. The results obtained for five organic acids or their salts are given in Table $3 ; 148$ isolates grew with succinate, acetate, lactic acid, formate, 1-malate or citrate acid as the sole added carbon source. These results are similar to those of Seleen \& Stark (1943) except that none of their organisms utilized formate; however, they used a $0 \cdot 3 \%(\mathrm{w} / \mathrm{v})$ concentration while only $0.1 \%$ was used here. The results of some preliminary work concerning these simple growth tests are worth noting. It was found that for acetate or succinate utilization the Koser-type basal salts medium was more favourable for 
growth than the Dowson-type medium, e.g. in one experiment 100 isolates did not grow in Dowson-type medium + acetate, whereas only 23 isolates did not grow after 14 days of incubation in the Koser-type basal medium + acetate. The concentration of carbon source was also important, but more so in the Dowson-type basal medium and particularly with acetate: e.g. 17/69 isolates did not grow in $1.0 \%$ acetate medium but grew well in the presence of 0.1 or $0.5 \%$. A further 16 isolates did not grow in $0.5 \%$ acetate but grew in $0.1 \%$ acetate in Dowson-type basal medium. Another concentration effect was also found in the $1.0 \%(\mathrm{w} / \mathrm{v})$ lactic acid medium, in which two isolates $(18 / 3, \mathrm{~d} 133)$ did not grow, but they did grow with $1.0 \%$ ammonium lactate in a Koser-type salts medium.

\section{Table 3. The utilization of organic acids by 169 isolates of Pseudomonas}

The inorganic salts + citrate medium of Koser (1932) was used, and also the same basal medium but with citric acid replaced by $(\%, w / v): 1.0$ sodium succinate; 1.0 lactic acid; $1.0 \mathrm{~L}$-malic acid; 0.2 sodium acetate; 0.1 sodium formate. + indicates growth; - indicates no growth.

\begin{aligned} & \multicolumn{1}{c}{ Isolate } \\ & d152 P. viridilivida \\ & $23 / 1$ From Ilex lesions \\ & $18 / 3$ From Primula lesions \\ & 55 From puddle \\ & d236 P. lacrymans \\ & $27 / 3$ From water works \\ & d270 P. mors-prunorum \\ & d133 P. primuli \\ & d221 P. tabaci \\ & d281 P. syringae \\ & $10 / 1$ From mollusc tank \\ & d248 P. atrofaciens \\ & d260 P. aptata \\ & 7810 P. hydrophila \\ & $18 / 2$ From Primula lesion \\ & d72 P. delphini \\ & d64 P. savastanoi \\ & d69 P. tolaasii \\ & d300 P. pisi \\ & $25 / 2$ Probably Xanthomonas \\ & d73 P. mori (peritrichous \\ & flagellation) \\ & Remaining 148 isolates \end{aligned}

\begin{tabular}{cccccc} 
Succinate Acetate & \multicolumn{6}{c}{ Lactate } & Formate & Lalate Citrat \\
- & + & + & + & + & + \\
- & + & + & + & + & + \\
+ & + & $-*$ & + & + & + \\
- & - & + & + & + & + \\
- & + & - & + & + & + \\
+ & - & + & - & + & + \\
- & - & - & + & + & + \\
- & - & $-*$ & + & + & + \\
- & - & - & + & + & + \\
- & - & - & + & + & + \\
- & - & + & - & + & + \\
- & - & + & - & + & + \\
+ & - & - & - & + & + \\
+ & + & - & - & + & - \\
- & - & - & - & + & + \\
- & - & - & - & + & + \\
- & - & - & - & + & + \\
- & - & - & - & + & + \\
- & - & - & + & - & + \\
- & - & - & - & - & - \\
- & - & - & - & - & - \\
+ & + & + & + & + & +
\end{tabular}

* Grew in $1.0 \%$ ammonium lactate medium

The effect of a growth factor supplement ( $0.03 \%, w / v$, Difco yeast extract) to the Dowson-type + acetate or succinate media was investigated; with acetate 34/46 isolates, and with succinate $30 / 62$ isolates apparently grew only when yeast extract was present. But for many of these isolates, substitution with the Koser-type basal salts medium resulted in growth in the absence of yeast extract. This effect was confirmed in the case of formate utilization; yeast extract had no true growth factor effect on formate utilization when the Koser-type basal medium was used. 
Further work is necessary concerning tartaric acid utilization because the results were not always repeatable, and the exact chemical (isomeric) nature of the tartaric acid crystals used was not ascertained. At least $44 \%$ of the isolates used this acid as a sole added carbon source. The oxidation of the various isomers of tartaric acid by $P$ seudomonas fluorescens was reported on by Martin \& Foster (1957) and for a soil Pseudomonas sp. by Shilo \& Stanier (1957).

In the $0 \cdot 1 \%$ oxalic acid Dowson-type medium 81/169 isolates developed a slight, although definite, turbidity after 3-7 days; there was little increase in opacity on further incubation. Similar growth was, however, obtained after two subcultures into tubes of similar medium. This restricted growth may have been due to an unfavourable basal medium, the limited amount of oxalate, or to carbon impurities in the medium. It was found that all the positive isolates developed a similar slight turbidity in the control medium which did not contain any added carbon source. Because of these results the calcium chloride+ potassium oxalate agar method of Jayasuriya (1955) for the direct detection of oxalate-decomposing pseudomonads and vibrios was also used. Although all the isolates grew on this medium none gave any reaction indicative of oxalate decomposition; compare Pseudomonas oxaliticus (Khambata \& Bhat, 1953).

(c) Utilization of carbohydrates as sole added carbon sources. The first routine investigation revealed that 40 of the isolates did not grow in the D-glucose medium. The test was repeated five times and altogether 64 isolates did not grow in at least one test. Further investigations with simultaneously replicated cultures, different sizes of inoculum, media in which the glucose was separately sterilized by either steaming, autoclaving or Seitz-filtration, and also with different single colonies of a given isolate as inoculum, were carried out. The results of this work may be summarized as follows. (i) There was often poor agreement of results when quadruplicate series of glucose + salts cultures were inoculated simultaneously from the same $24 \mathrm{hr}$. YE broth culture. (ii) The size of the inoculum (i.e. straight wire or $4 \mathrm{~mm}$. loop) was only rarely important, but there was a tendency for the larger inoculum to establish itself more frequently. (iii) There was a strong indication that heat-sterilization of the complete medium produced a medium inhibitory to the growth of at least $46 \%$ of the isolates; heat-sterilization of the glucose solutions separately, either by steaming or autoclaving, only rarely inhibited growth. Apparently the substance(s) in the inhibitory medium was actively toxic and not merely bacteriostatic, because after 14 days of incubation the 'no growth' tubes contained no viable organisms, while controls remained viable for 6 weeks in sterile tap water. Some isolates were more consistently affected by the supposed inhibitory compound(s) than others. This sensitivity was not confined to the known plant pathogens. (iv) Cultures derived from different single colonies of an isolate frequently showed different sensitivities toward the hypothetical inhibitory substance(s) in the steam-sterilized $\left(100^{\circ}\right)$ complete glucose medium; even cultures inoculated from different zones of the same colony showed different results in $21 / 35$ instances. The slime produced by mucoid colonies had no protective effect. Altogether 273 colonies or parts of 
colonies from 66 isolates were tested in duplicate in the steam-heated complete glucose medium, and in medium to which glucose separately sterilized by Seitz-filtration was added. Of the colonies tested $37 \cdot 3 \%$ showed a sensitivity towards the supposed inhibitory compounds formed when the complete glucose + ammonium + salts medium was sterilized at $100^{\circ}$. Finally, even when the glucose was sterilized separately seven isolates were unable to use it as a carbon source for growth in the Dowson-type ammonium + salts medium. Apart from isolate $\mathrm{d} 73$, all these isolates were named phytopathogenic Pseudomonas spp., so that non-utilization of glucose under these conditions seems to be a real property of a few pseudomonads.

Because of the above results, similar 'no growth' phenomena in other carbohydrate-containing media were confirmed with separately sterilized carbohydrate solutions. Mannitol, salicin and sucrose sometimes caused inhibition of growth, but not so often as glucose.

Galactose, fructose, maltose, $\mathrm{D}$ - and L-arabinose, lactose and cellobiose did not cause any similar growth inhibition. This extends the reports of sugarcontaining media which inhibit the growth of other bacteria; see Lewis (1930) for Phytomonas (Xanthomonas) malvacearum; Stanier (1942) for Cytophaga; Jensen (1951) and Parker (1955) for Azotobacter (see also van Steveninck, 1958).

The results of 17 out of 23 of the carbohydrate-carbon utilization tests are given in Fig. 1. For the six remaining substrates, dextrin, starch, cellulose, inulin, salicin and dulcitol, it was found that with very few exceptions a certain 82 isolates showed a slight to moderate, but distinct, turbidity. For these same 82 isolates, slight turbidities had also been recorded in the oxalate medium (see above). Furthermore, precisely these 82 isolates showed a similar slight growth in the control medium which contained no added carbon source; possibly growth occurred at the expense of intracellular food reserves or of carbonaceous impurities in the medium. Garvie (1955) reported experiments in which Pseudomonas fuorescens grew (to 1-10 million organisms/ml.) and was repeatedly subculturable in a very pure solution of phosphate buffer; it was claimed that there was no significant carry-over of nutrients, and that growth was not supported by dead organisms. A similar very small degree of multiplication (not giving growth visible to the naked eye) of $\boldsymbol{P}$. fuorescens was reported by Englesberg \& Stanier (1949) in studies on itaconate-utilizing mutants. Because of these reports, the correlating carbohydrate-utilization tests are recorded as one character only in Fig. 1, in the 'control, minus carbon' column.

Note i. Concerning aesculin utilization. There was finally good agreement in the results with the four methods of test for aesculetin formation. The micromethod was the most rapid; isolates usually gave a definite reaction after incubation for $24 \mathrm{hr}$. although a few required 3 days. Sneath's agar plate method was preferable to his broth method because of greater rapidity and sharpness of results. There was no correlation between the ability to hydrolyse aesculin and any other character tested. This was disappointing in comparison with its usefulness in the classifying of the closely-related genus Chromobacterium (Sneath, 1956a). 


\section{Pseudomonas fluorescens}

Note ii. Falsely positive growth results were obtained when the liquid starch medium was used, except in the case of the two Aeromonas spp. which both grew rapidly in the medium, producing dense turbidity, acid and gas; they also grew rapidly and were the only isolates to produce acid and gas from dextrin and maltose. By the traditional starch agar plate method, only these two isolates hydrolysed starch significantly. Preliminary experiments showed that the concentration of starch in the YE agar was important $(0.1 \%, \mathrm{w} / \mathrm{v}$, optimal) and on such iodine-flooded starch cultures about 20 Pseudomonas isolates showed ill-defined reddish zones indicative of erythrodextrin formation. Several more isolates were feebly diastatic, showing signs of hydrolysis only immediately below the areas of growth. There was no agreement between the liquid starch medium results and the feeble reactions on starch agar; it was concluded that the only value of this test in this survey was for the detection of Aeromonas spp. Some feeble starch reactions were found also by Clara (1934), but all the 199 isolates of Seleen \& Stark (1943) were non-diastatic.

Note iii. Simon (1956) suggested that the fermentation of D-arabinose in peptone-free medium differentiated $P$ seudomonas aeruginosa from $P$. fluorescens. This was not confirmed in the present work because only 24 isolates did not utilize D-arabinose; however after only $48 \mathrm{hr}$. of incubation many $P$. fluorescenstype isolates showed only sparse growth. L-Arabinose was used more rapidly, but the $\mathrm{D}$-form was not utilized faster by the pyocyanine-producers and at least five fluorescens-type isolates utilized both isomers with equal facility. Palleroni \& Doudoroff (1957) found that mutants of $P$. saccharophila were able to oxidize $D$-arabinose; Lockwood \& Nelson (1946) reported oxidation of D- and L-arabinose by $\boldsymbol{P}$. fragi, $\boldsymbol{P}$. graveolens and $\boldsymbol{P}$. vendrelli.

(d) Aerobic versus anaerobic glucose utilization. When stab cultures in Hugh \& Leifson's (1953) medium were sealed with paraffin as described in Methods 165 of 169 isolates did not grow at all. The two Aeromonas isolates showed rapid growth; an acid reaction and gas bubbles developed after $18 \mathrm{hr}$. Pseudomonas isolate 55 was acid after 18 days, and isolate $36 / 1$ showed a slight acid reaction (only in the centre of the stab) after 18 days; no growth was visible with those two isolates. Unsealed (aerobic) replicate cultures typically showed an acid reaction, developing first (within 4 days) at the surface, but completely throughout the culture after 7 days. There were a few exceptions to this; the aeromonads showed acid and gas after $24 \mathrm{hr}$.; 3 isolates grew but were not acid even after 28 days, and 7 isolates grew well but showed only a slight degree of acidity after 7 days which did not intensify on further incubation. In detail these reactions to glucose in a peptone medium did not agree completely with glucose utilization in chemically defined medium, but the usefulness of the test for the differentiation of Aeromonas from the obligately oxidative Pseudomonas as pointed out by Hugh \& Leifson, was confirmed.

(e) Gluconate test. One hundred and ten isolates grew well in the Koser-type basal medium with gluconate as carbon source, and after incubation for 7 days gave a strong positive reaction after $10 \mathrm{~min}$. boiling with Benedict's qualitative solution, indicative of 2-keto-D-gluconic acid production. Twentyeight isolates grew well but gave only a weak reaction after 7 days of incubation, 
although $\mathbf{1 7}$ of these showed a good reduction after only 4 days; presumably the 2-keto-D-gluconic acid was further metabolized during the 4- to 7-day period of incubation. Of the remaining 31 isolates, 24 grew well but with no indication of reduction at 2, 4, or 7 days; 7 isolates did not grow. Haynes (1951) considered the ability to form reducing substances from gluconate as a character useful (in conjunction with others) for the identification of Pseudomonas aeruginosa; the present results lend no support for emphasis of this criterion. Gaby (1955) reported 2-keto-D-gluconic acid production by many strains of Proteus and paracolon bacteria, and Katznelson (1955) for 6 phytopathogenic Pseudomonas spp. and other phytopathogens.

(f) Voges-Proskauer and Methyl Red tests. All except the 7 isolates which failed to grow in the Fouad \& Richards glucose salts medium were MR-positive after 7 days. This was in agreement with the known ability to produce acid from glucose by an oxidative process. All the $\mathrm{V}$-P results were negative as far as could be ascertained, but on heating with $40.0 \%(\mathrm{w} / \mathrm{v}) \mathrm{KOH}$ solution a bright yellow colour developed, probably due to the intensification of the colour of fluorescent pigments at the alkaline $\mathrm{pH}$ value, so that the results were difficult to interpret. Thus these two tests are of limited use as diagnostic criteria for pseudomonads. The V-P negative reaction of the Aeromonas isolates was not in agreement with Miles \& Miles (1951) who found both these NCTC isolates to be V-P positive, but these workers used a nutrient broth medium, which may explain the discrepancy.

(g) Utilization of phenol, m-cresol, naphthalene, ethanol and glycerol. Phenol and $m$-cresol at $0.1 \%(\mathrm{w} / \mathrm{v})$ were not utilizable as sole carbon sources. These tests were carried out because of reports that Pseudomonas phenolis n.sp. (Hamdy et al. 1956) could use these compounds. The general properties of this species differed from fluorescens-type organisms; e.g. $\boldsymbol{P}$. phenolis grew well at $54^{\circ}$ but not at $10^{\circ}$ and it was very inactive biochemically. Eighty pseudomonad isolates showed a definite subculturable turbidity in the naphthalene medium, but these isolates were identical with those which grew in the control basal medium to which no carbon source had been added. Klausmeier \& Strawinski (1957) obtained from soil naphthalene-oxidizing isolates which they identified as $P$. aeruginosa; Fernley \& Evans (1958) reported that some Pseudomonas isolates from conifer litter oxidized naphthalene and other polycyclic hydrocarbons; utilization of naphthalene as carbon source may have occurred in my experiments.

Sixty-eight isolates grew in the ethanol medium and typically showed an acid reaction after 7 days; these were all isolates which grew in the 'minuscarbon' control medium, so the significance of this growth with ethanol seems doubtful. One randomly selected isolate (43/2) was, however, subcultured (inoculation by straight wire) more than 20 times in the ethanol medium, and dense suspensions of these organisms rapidly oxidized ethanol when tested by Warburg manometric techniques (cf. Stanier, 1947).

Glycerol was readily utilized; only 14 isolates did not grow on basal salts medium + glycerol.

(h) Utilization of ammonium-N. Only isolates $25 / 2, \mathrm{~d} 73$ and 7810 (all con- 
sidered on other evidence not to be Pseudomonas spp.) did not grow when supplied with ammonium-N in Koser's citrate medium, although 11 isolates (mostly phytopathogens) required 3 days of incubation before developing a turbidity visible to the naked eye; the final degree of turbidity was also less than that of the other pseudomonads. However, the same isolates also showed a slower and less dense growth in a peptone + growth factor medium. The results noted in one set of control tubes (galactose + inorganic salts but no added nitrogen; potassium phosphate substituted for ammonium phosphate) were surprising: 77 isolates gave a definite acid reaction to bromocresol purple (yellow at pH 5.2) within 3-14 days. Of these isolates $88.3 \%$ showed acidity and slight turbidity after straight-wire subculture into similar medium; 7 more isolates showed later growth but not acid production. Whether intracellular nitrogenous food reserves, atmospheric nitrogen, or nitrogenous impurities in the medium or in the air, were being used by these actively metabolizing control cultures was not ascertained. Nitrogen-fixing bacteria of the genus Pseudomonas appear to be common (Anderson, 1955; Proctor \& Wilson, 1958). Jannasch (1958) reported that the growth of $\boldsymbol{P}$. fluorescens was not limited until the nitrogen concentration was less than $0.01 \mathrm{mg}$. ammonium- $\mathrm{N} / \mathrm{ml}$. (slightly higher for nitrate- or amino-N).

(i) Utilization of nitrate- $N$. For all except 6 isolates turbidity developed more rapidly with ammonium- $\mathrm{N}$ rather than the nitrate- $\mathrm{N}$ in defined medium; when the final turbidities were visually compared only $16 \%$ of the isolates showed about equal turbidities in both media. Of the isolates, $57 \%$ showed very slight or no turbidity in the nitrate medium; this should be contrasted with the results of Seleen \& Stark (1943) who found that $92.5 \%$ of 199 strains of fluorescent pseudomonads were able to grow well on a nitrate+ glucose + inorganic salts medium; they detected nitrite in $86 \%$ of their cultures. Sometimes a slight amount of growth was obtained in the present work under anaerobic conditions; two Pseudomonas aeruginosa isolates and the two Aeromonas isolates showed more turbidity. Strict anaerobiosis completely prevented growth of $123(74 \cdot 6 \%)$ isolates.

All cultures which showed any turbidity gave a positive reaction with Nessler's solution after 7 days. The results of the tests for nitrate-reduction in the chemically defined medium were the same, whether the cultures were incubated aerobically or anaerobically. Traces of nitrite were often noted; but when these are ignored (this is deemed valid because such weakly positive results were not constant on retesting) a close agreement between the results with the four test methods was evident. Only those 46 isolates which were able to reduce nitrate aerobically were able to grow anaerobically, and then only when nitrate was present. Gas production was not an absolutely constant feature, even when using the same chemically defined medium; 40 nitriteforming isolates usually showed gas production as well, but 6 never did so. During the survey loss of nitrate-reducing ability was noted once only (isolate 42/2).

(j) Utilization of nitrite- $N$. Sodium nitrite at $0.05 \%(w / v)$ was found to be non-toxic in a galactose + salts medium, although the growth of $14 \%$ of the 
isolates was inhibited by $0 \cdot 1 \%(\mathrm{w} / \mathrm{v}) \mathrm{NaNO}_{2}$. Cultures in the salts + galactose + nitrite + bromocresol purple medium never showed more than a trace of turbidity, similar to that in the control medium without added nitrogen source. Thus it appeared that nitrite- $\mathrm{N}$ was not a suitable source of nitrogen. However when compared with growth in the control tubes it was seen that the addition of nitrite resulted in some real differences in degree of growth, namely: (i) $48 \%$ of the isolates were able to oxidize galactose only when nitrite was supplied; (ii) $43 \%$ of the isolates produced acid at least $48 \mathrm{hr}$. sooner in the presence of added nitrite. Nevertheless, the nitrite had not disappeared from the medium when 7-day cultures were tested with the Griess-Ilosvay reagents. Only when the complete Koser's citrate medium (containing ammonium-N) + $0.0005 \%(\mathrm{w} / \mathrm{v})$ sodium nitrite was used did 40 isolates decompose all the nitrite within 7 days. These same 40 isolates also decomposed the $0.0005 \%$ nitrite in the semi-solid YE agar within 5 days. The microtest also showed that the same 40 isolates caused nitrite disappearance after incubation for $2 \mathrm{hr}$. Of the 46 nitrate-reducing isolates, 6 never produced gas, and these 6 isolates were unable to reduce nitrite. No isolate was found to reduce nitrite but not nitrate. The disappearance of nitrite only when some other nitrogenous source was present was observed by Seleen \& Stark (1943).

(k) Utilization of urea. All isolates grew within $48 \mathrm{hr}$. on Christensen's medium and all but three developed an alkaline reaction during 2-28 days; the period differed according to the isolate. No clear differentiation of isolates was possible and it seemed likely that with such proteolytic organisms the alkaline reaction might be of double origin, from the peptone and/or from the urea.

In the low-galactose + salts + urea medium, 81 isolates did not grow. After 31 days of incubation the $\mathrm{pH}$ value of the remaining 88 cultures differed; 51 were alkaline, 16 were acid and 21 were approximately neutral. The 51 alkali-yielding isolates did not show a particularly rapid or intense alkaline reaction on Christensen's medium, so urea breakdown seems doubtful. Nearly all the 88 isolates apparently growing in the urea medium also developed a similar turbidity in control cultures without added nitrogenous compound; thus urea breakdown was not proven for any isolate. De Turk (1955) reported the adaptive formation of urease in washed suspensions of Pseudomonas aeruginosa.

\section{Biochemical tests}

(a) Catalase production. All isolates gave a definite, rapid and positive reaction indicative of the presence of catalase when $24 \mathrm{hr}$. YE agar-grown organisms were tested with hydrogen peroxide.

(b) Ammonia production from peptone. After 7 days in peptone water all cultures showed a definite turbidity and the $\mathrm{pH}$ values of the media were between $8 \cdot 3$ and $8 \cdot 7$ (majority $8 \cdot 6$; control $7 \cdot 25$ ). Every culture showed a more positive ammonia reaction than the control tube (cf. Seleen \& Stark, 1943). Some of this alkalinity was probably due to ammonia production, but alkaline products of proteolysis (e.g. amines or amides) may also have been produced.

(c) Haemolysis. All isolates grew within $48 \mathrm{hr}$. on YE agar +horse-blood, but the detection of haemolysis was difficult because of the presence of pigments 
and partially clear zones of haemolysis. Only the two Aeromonas isolates gave zones of clear and complete haemolysis within $48 \mathrm{hr}$.; two isolates of Pseudomonas aeruginosa showed complete haemolysis after $\mathbf{3}$ days but $\boldsymbol{P}$. aeruginosa 21 showed only a wide zone of ill-defined haemolysis. Many other isolates showed clearing underneath the growth, or a zone of partial clearing $c .2 \mathrm{~mm}$. wide. After 5 days all plates showed complete haemolysis. Thus this test was not very useful except for differentiating Aeromonas from pseudomonads, and confirms the opinion of Liu (1957) that animal-pathogenic and non-pathogenic pseudomonads may produce haemolysis and that the character cannot be used for species identification.

(d) Reaction on egg-yolk agar medium. After incubation for 2 days a dense white precipitate surrounding the growth was apparent with 100 isolates; 23 other isolates gave a positive reaction after 3-7 days. The remaining 46 isolates grew equally well but showed no precipitate around the growth even after prolonged incubation, although clear zones (perhaps due to lipolysis or proteolysis) were sometimes apparent.

(e) Gelatin hydrolysis. All isolates except d 73 grew on the nutrient gelatin medium typically on the surface only; production of pigment was only rarty seen with gelatin although on Difco Bacto gelatin good pigmentation occurred. No clear-cut demarcation between rapidly- or slowly-liquifying isolates was obvious. Regardless of whether liquifaction was stratiform or saccate, an initially rapid rate of liquifaction was not always maintained. The shape of liquifaction round the stabs was not constant for a given isolate, and this perhaps accounted for some of the apparently variable rates of liquifaction. This was further suggested in comparative experiments with nutrient gelatin stabs and streak cultures on Frazier's gelatin agar. Certain saccately-liquifying isolates apparently hydrolysed gelatin more rapidly than certain stratiformtype slower liquifiers; but all gave a $10 \mathrm{~mm}$. zone of hydrolysis on Frazier's gelatin agar after 3 days.

For 67 isolates the rate of liquifaction slowed down considerably with increasing length of maintenance of stock cultures in YE broth. Eight isolates once lost the gelatin-liquifying property completely; of these the initial hydrolytic activity was not always feeble and the losses occurred at different dates. Because of the taxonomic use which has been made of this feature, the gelatinliquifying ability of the mineral oil-preserved cultures was compared with that of the 'bench-broth' stock cultures. For 63/67 isolates the decreased rates or losses of liquifying ability when the 'bench-broths' were used for inoculation were confirmed. Once the hydrolytic power was lost by a culture it was never seen again during subsequent routine examinations.

The absence of any liquifaction after 7 days was not conclusive; frequently some hydrolysis was evident after 8-28 days. The possibility that the $1.0 \%$ peptone in the nutrient gelatin was perhaps competing with gelatin as a nutrient was considered. Twenty-eight slowly-liquifying isolates were stabinoculated into the gelatin + yeast extract (minus peptone) medium and into ordinary nutrient gelatin simultaneously. Twenty-two isolates showed the same rate of liquifaction in both media; 5 liquified the non-peptone medium 
more rapidly, and one isolate showed slower liquifaction of the non-peptone medium. Further, isolates which had lost the ability to digest gelatin within 28 days on peptone-gelatin medium were not induced to do so in the absence of peptone, although surface growth was still apparent. Therefore the absence of peptone was not particularly advantageous, but the inclusion of it in nutrient gelatin was unnecessary for this collection of pseudomonads. The slowlyliquifying isolates showed signs of gelatin digestion no more rapidly on Frazier's medium. For $\mathbf{7 9}$ isolates the extent and rate of gelatin liquifaction remained fairly constant during 4 years. However, the importance of the gelatin-liquifying ability as a diagnostic character for $\boldsymbol{P}$ seudomonas must be assessed with care. The graded series of rates of hydrolysis encountered here, from very rapid to very slow, together with the instability of the character, and the fact that different sources of gelatin may give different results, suggest that the character is not well suited for classification purposes. The writer agrees with Hormaeche \& Munilla (1957) that gelatin liquifaction does not deserve the importance that has been attached to it.

(f) Liquifaction of pectate gel. Only two non-pseudomonads failed to grow in the calcium pectate stabs, but not one isolate liquified this medium (Erwinia carotovora effected liquefaction after $48 \mathrm{hr}$.). Pectinase and/or pectase activity has been reported for several phytopathogenic pseudomonads, e.g. (Thornberry (1938) for Pseudomonas angulata; Oxford (1944) for P. marginalis and $P$. syringae; Erikson (1945); Mills (1949); Paton (1958). My results are not in agreement because neither isolate $\mathrm{d} 263$ ( $P$. angulata) d 281 ( $P$. syringae) nor $\mathrm{d} 289$ ( $P$. marginalis) showed any trace of pectate degradation here.

(g) Action on milk. In litmus milk cultures usually only a slight acid or alkaline reaction change was observed during the first 3 days. Later, pigment production and/or reduction were usual; but in 47 isolates a strong alkalinity developed, which intensified on continued incubation. When checked electrometrically, after 7 days the $\mathrm{pH}$ value of the blue cultures ranged between $7 \cdot \mathbf{1}$ and $7 \cdot 8$ (control $6 \cdot 4$ ); after 14 days the values were $7 \cdot 5$ to $8 \cdot 3$ (control $6 \cdot 6$ ). After 14 days the alkaline cultures seemed to be clearing and the determination of simultaneous proteolysis was difficult. In the absence of de-amination it was difficult to account for the alkaline reaction. The work of Ayers, Rupp \& Johnson (1919) suggested an explanation, namely citrate utilization with concomitant bicarbonate formation. The milk agar plate method of testing was confirmatory: although the unmistakably proteolytic isolates effected the rapid formation of clear zones round the growth (not precipitated with acidified mercuric chloride) the intense alkali-producers gave no such indication of protein decomposition (occasional slight clearing disappeared on addition of the acidified mercuric chloride solution).

The rapid formation of a hard acid clot of milk protein was consistently characteristic only for the two Aeromonas isolates; 25 other isolates occasionally showed an acid clot, but at least 14 days of incubation were necessary. No correlation with lactose breakdown was noticed; it was concluded that because of the complex simultaneous reactions occurring in milk media, the phenomenon of hard clotting was not a very useful feature here. 
Unmistakable protein digestion was visible in many neutral (or near neutral) cultures of 91 isolates after 7 days; 30 other isolates showed definite digestion during 7-28 days. The rate of digestion varied according to the isolate; sometimes it was complete after 3 days, but with other isolates it was incomplete after 28 days and it was not possible to classify the isolates except as a continuous series. Furthermore, most of the isolates showed a slowingdown of the rate of protein digestion when inoculated from stock cultures maintained on YE broth. Only for 29 isolates did the rate remain the same; in 14 isolates proteolytic activity was apparently lost altogether by the 'bench-broth' stock cultures. Further experiments with liquid cultures and the milk-agar plate method confirmed that the 'bench-broth' mothercultures often showed much decreased rates or even complete loss of proteolytic activity toward milk, as compared with the mineral oil-preserved mother cultures.

All isolates which had lost the ability to produce proteolytic enzymes in milk were still able to grow in litmus milk with the development of marked alkalinity. They were indistinguishable from the 47 alkaligenic isolates which had always been non-proteolytic. Some isolates which initially attacked milk protein very rapidly lost this striking property, as well as isolates which originally possessed only feeble proteolytic activity.

Before, or concurrent with, the digestion of milk protein the formation of a soft rennet-type clot was usual. The medium was always nearly neutral (sometimes masked by pseudomonad pigments), and then proteolysis proceeded from the surface downwards, often resulting in banded horizontal strata in various stages of digestion. Non-proteolytic isolates never showed any rennin clotting.

The reduction of litmus or methylene blue was apparent from $48 \mathrm{hr}$. onwards in liquid milk cultures of all isolates; thus this character served no useful purpose for differentiation. Pigment production was a complicating factor and skim milk was found to be a good medium for its production. Only isolate $\mathbf{d 7 3}$ (not a pseudomonad) did not produce a change in milk.

One may conclude that milk protein digestion by Pseudomonas spp. is an unstable character. When freshly isolated, $71 \cdot 6 \%$ of the isolates were proteolytic and the remainder were alkaligenic (cf. 67\% proteolytic fluorescent pseudomonads in the collection described by Seleen \& Stark, 1943).

(h) Indole production. Regardless of whether a peptone or chemically defined tryptophan-containing medium was used, all isolates were indolenegative except the two Aeromonas isolates. Falsely positive reactions were noted in the pyocyaninogenic cultures of Pseudomonas aeruginosa, due to the formation of the red salt on adding the acid reagents.

(i) Production of hydrogen sulphide. When the isolates were grown on Kligler's iron agar (Oxoid) an alkaline reaction was produced, usually after $24 \mathrm{hr}$.; the phytopathogens often required 2 days. Seven isolates caused a blackening of the medium. In the chemically defined salts + cystine medium 12 isolates (including the 7 above) produced hydrogen sulphide, but the results were not always repeatable. The microtest gave more consistent results, 
although incubation for 6-12 hr. was usually necessary. Again the Aeromonas isolates were distinct in that they produced hydrogen sulphide rapidly and abundantly. Apart from this, this character was of minor taxonomic value; one $P$ seudomonas aeruginosa isolate was positive, three were negative. This agrees with the conclusions of Sherwood, Johnson \& Radotincky (1926); they found that only 11/22 isolates of $P$. aeruginosa blackened lead acetate agar.

The investigations concerning hydrogen sulphide production from thiosulphate were an outcome of the use of Kligler's medium which contains amino acids + thiosulphate. In the ammonium + galactose + salts + thiosu! phate medium, hydrogen sulphide was produced by most cultures, but incubation for 14 days was often necessary. With the microtest incubation for c. $4 \mathrm{hr}$. was sufficient and the results were more consistent: 135 isolates produced hydrogen sulphide ( 5 weakly positive) and 34 did not. When 'oil' and 'benchbroth' stock cultures were compared it was found that 8 cultures from 'benchbroths' had lost the property.

After comparison of the results it was apparent that the character showed no obvious relationship with any other property examined here, including nitrate reduction (similar roles of nitrate and thiosulphate as hydrogenacceptors postulated). Nor was there any relationship between hydrogen sulphide production here and in Kligler's medium or in the cystine medium. The significance of the thiosulphate-reducing reaction is not yet understood. It may be a useful diagnostic character, but the loss of the property by 8 isolates indicates some instability.

(j) Hydrolysis of tributyrin. There was extremely good agreement among the tributyrin hydrolysis results, both qualitatively and quantitatively (as measured by zone width) during four years of testing, with 5 exceptions in which the loss of tributyrinolytic activity by the 'bench-broth' stock cultures was noted, and confirmed by the retention of this property by the oil-preserved stock cultures. Incubation for 7 days was adequate and enabled detection of even the slowly hydrolysing isolates. A zone of hydrolysis of less than $2 \mathrm{~mm}$. after incubation for 7 days was disregarded because of reports of limited spontaneous hydrolysis of tributyrin, and the liberation of endocellular tributyrinases on lysis (Sierra, 1957a,b). Concerning the reported toxicity of tributyrin for some micro-organisms (Collins \& Hammer, 1934), although pseudomonad growth was sometimes locally sparse, a $4 \mathrm{~mm}$. loopful of inoculum was sufficient to overcome the slight toxicity; only isolate $\mathrm{d} 73 \mathrm{did}$ not grow. Altogether 138 isolates (82.2\%) hydrolysed tributyrin and 30 did not.

(k) Hydrolysis of olive oil. Thirty-nine isolates showed no sign of blue salt formation on the olive oil medium. Thirty of these also did not hydrolyse tributyrin but of the remainder, 8 weakly hydrolysed tributyrin. Isolate $\mathbf{d r 3}$ did not grow on the olive oil medium. Thus 130 isolates were lipolytic on both olive oil and tributyrin media. Sixteen of the olive oil-negative isolates did not grow at all; the remainder grew to an extent similar to that on control medium without olive oil. A positive reaction (heavy blue coloured growth) developed rapidly, usually after $24 \mathrm{hr}$.; but isolate $8 / 6$ required 7 days.

(l) Hydrolysis of margarine. The similarity of the results on the olive oil 
and margarine medium was very marked because the same 39 isolates were non-lipolytic, and isolate $8 / 6$ was only slowly positive on both media. The remaining 130 isolates all gave a rapid and definite positive reaction. This agrees with Goldman \& Rayman (1952) who reported that Pseudomonas strains often differed widely in the rate and extent of hydrolysis of various fats, but rapid lipolysis was common in Pseudomonas fluorescens-type organisms. They also made the important observation that the susceptibility of different fats to hydrolysis depended on the particle size of the emulsion and not on the chemical composition of the fat; they standardized the globule size by means of a soy phospholipid emulsifying agent.

(m) Hydrolysis of Tween 80. The three tests carried out in 1957 showed good agreement; 120 isolates were able to hydrolyse this non-glyceride ester of oleic acid. Eighty-six isolates showed dense zones of calcium oleate crystals round the growth after 3 days; 34 other isolates were positive after 7 days. All the isolates which hydrolysed Tween 80 were also able to hydrolyse tributyrin, olive oil and margarine. However, of the 49 isolates which did not hydrolyse Tween 80 and which all grew well on the medium, 8 were able to hydrolyse tributyrin, and 31 were negative on both media. These observations agree with those of Sierra (1957 $b$ ) and Greuell \& Sierra (1957) who presented convincing evidence that $\boldsymbol{P}$ seudomonas aeruginosa possesses different esterases specific for tributyrin and Tween 80, respectively, but that one enzyme, 'lipase', will hydrolyse Tween 80 or olive oil.

\section{DISCUSSION}

Many conclusions are possible from the results recorded during this survey; only the major ones can be considered here. During a period of at least 5 years the stability of each character was assessed. Even under the reasonably standardized conditions used, certain characters were not constant. These included: number of flagella/rod, colonial morphology on nutrient media or on potato slopes, pyocyanine or fluorescin production. Other characteristics were found to change when the isolates were stored in YE broth; these included the ability to digest milk protein, to liquefy gelatin, to produce hydrogen sulphide from thiosulphate, to hydrolyse tributyrin and to reduce nitrate. Frequently there was a decrease in the rate of a given reaction with increasing periods of maintenance in YE broth: this was particularly noticeable in the milk and gelatin media. Table 4 is given to show that the loss of one character was not necessarily associated with the loss of others, and that certain isolates were more unstable than others. It may be emphasized that all the results were based on a 28-day period of incubation (a disadvantage for identification purposes in diagnostic bacteriology, but essential in classification studies). Very different positive and negative results were recorded after 1, 2, 3, 4, 7, 14, 21 or 28 days of incubation.

Scrutiny of the final results showed that the following characters were common to all the isolates tested:

(1) Gram-negative, non-endospore-forming rods with an average size of $1 \cdot 5-2 \cdot 0 \times 0 \cdot 5-0 \cdot 6 \mu$ (range $1 \cdot 0-3 \cdot 0 \times 0 \cdot 5-0 \cdot 7 \mu)$. 
(2) Able to grow aerobically within $48 \mathrm{hr}$. at $25^{\circ}$ on YE agar or YE broth initially at $\mathrm{pH} \mathbf{7 \cdot 2}$.

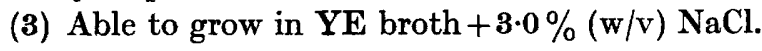

(4) Catalase-positive.

(5) Produce ammonia when grown in peptone water medium; after 7 days the $\mathrm{pH}$ value of the medium is $c . \mathbf{8 \cdot 6}$.

Table 4. Isolates of Pseudomonas which showed losses of physiological characters when maintained on yeast-extract peptone medium.

Lost character

\begin{tabular}{|c|c|c|c|}
\hline $\begin{array}{c}\text { Milk } \\
\text { protein } \\
\text { digestion }\end{array}$ & $\begin{array}{l}\text { Hydrolysis } \\
\text { of } \\
\text { tributyrin } \\
\text { Isol }\end{array}$ & $\begin{array}{c}\text { Liquefaction } \\
\text { of } \\
\text { gelatin }\end{array}$ & $\begin{array}{l}\text { Reduction } \\
\text { of } \\
\text { thiosulphate }\end{array}$ \\
\hline • & . & . & $4 / 2$ \\
\hline . & . & $5 / 5$ & . \\
\hline $5 / 10$ & . & $5 / 10$ & . \\
\hline . & . & $8 / 1$ & $8 / 1$ \\
\hline . & . & . & $8 / 9$ \\
\hline $9 / 4$ & . & . & . \\
\hline . & - & . & $10 / 3$ \\
\hline . & . & $12 / 3$ & . \\
\hline $12 / 5$ & $12 / 5$ & . & . \\
\hline $15 / 6$ & . & . & . \\
\hline $16 / 1$ & . & . & . \\
\hline $18 / 3$ & $18 / 3$ & . & $18 / 3$ \\
\hline $22 / 2$ & $22 / 2$ & . & . \\
\hline . & $22 / 3$ & . & . \\
\hline $22 / 5$ & . & . & $22 / 5$ \\
\hline $35 / 1$ & . & $35 / 1$ & $85 / 1$ \\
\hline . & . & . & $36 / 4$ \\
\hline • & . & $40 / 2$ & . \\
\hline . & $40 / 3$ & $40 / 3$ & . \\
\hline $42 / 1$ & . & . & . \\
\hline • & . & - & . \\
\hline $47 / 5$ & . & . & . \\
\hline 49 & . & . & . \\
\hline $52 / 1$ & . & . & . \\
\hline $52 / 2$ & . & • & . \\
\hline$\cdot$ & - & d152 & . \\
\hline 14 & 5 & 8 & 8 \\
\hline
\end{tabular}

One isolate $(42 / 2)$ lost ability to reduce nitrate

Examination of the results of the remaining tests showed that 4 isolates were distinctly different from the rest. First, isolates 7810 (NCTC; Pseudomonas hydrophila) and 8049 (NCTC; $P$. icthyosmia) are the only ones with the following characters: $(a)$ grow anaerobically with the production of acid and gas from glucose; $(b)$ no growth in the presence of the pteridine derivative $0 / 129$; (c) produce acid and gas aerobically from carbohydrates (glucose, galactose, L-arabinose, glycerol, mannitol, rhamnose, trehalose, sucrose, lactose); $(d)$ show definite diastatic activity on starch agar; $(e)$ show rapid heavy growth with acid and gas production from starch, dextrin and maltose; $(f)$ produce 
abundant hydrogen sulphide rapidly from cystine or thiosulphate in chemicallydefined media, or in Kligler's medium; $(g)$ show distinct $\beta$-type haemolysis on horse-blood agar; $(h)$ produce indole from peptone or tryptophan; $(i)$ show rods with only one polar flagellum. These two isolates are considered to belong to a different genus, namely, Aeromonas Kluyver \& van Niel, and will not be further discussed.

Secondly, isolate d73 (WJD; $P$. mori) was a larger and constantly peritrichously-flagellate rod. Other characters peculiar to it were: inability to grow in litmus milk, on nutrient gelatin, on potato slope, on tributyrin agar or on pectate gel; inability to use ammonium-N (e.g. no growth in Koser's citrate medium); sensitivity to the pteridine derivative $0 / 129$; markedly rough and rhizoidal colonial growth; inability to grow in $\mathrm{YE}$ broth of initial $\mathrm{pH}$ 5.5. It is difficult to place this isolate in an appropriate genus.

Thirdly, isolate 25/2 (a laboratory aerial contaminant) produced a distinct orange-yellow water-insoluble pigment when grown on YElagar, and did not utilize ammonia-N and therefore would not grow in any of the chemically defined media used here. Growth was not stimulated by the addition of $0.03 \%$ yeast extract (Difco) and it did not grow on the pectate medium. This organism is possibly a Xanthomonas Dowson; it was not monotrichous and had many properties in common with the rest of the collection.

Next may be considered the other properties characteristic of the remaining 165 isolates, namely:

(6) All isolates showed some rods with polar flagella, but the number of flagella/rod, amphitrichy and flagellar curvature were variable.

(7) Exocellular slime formation was typical, but the amount varied from abundant to very slight; environmental factors such as the age of culture and the nature of the medium were important controlling factors.

(8) Colonial appearance on YE agar was very variable.

(9) All were obligate aerobes; no growth occurred in glucose + peptone water under strictly anaerobic conditions.

(10) Able to grow at $12-30^{\circ}$; no clear-cut temperature optima.

(11) Able to grow in YE broth initially at $\mathrm{pH} 5 \cdot 5$.

(12) Not able to grow in YE broth initially at $\mathrm{pH} 4.5$ or 4.0 .

(13) Growth not inhibited by the pteridine derivative 0/129.

(14) Able to use ammonia- $\mathrm{N}$ when supplied as the sole source of added nitrogen in an inorganic salt medium.

(15) Able to grow in Koser's citrate medium or in a similar medium with citrate replaced by sorbitol.

(16) No stimulation of growth in the simple chemically defined media used here by addition of Difco yeast extract.

(17) Not able to decompose oxalate visibly when inoculated on calcium chloride + potassium oxalate agar, although growth occurred.

(18) No significant growth (i.e. more than in the control medium without added carbon source) when starch, dextrin, cellulose, inulin, salicin or dulcitol was supplied as the sole added carbon source.

(19) Able to grow in gelatin medium (no peptone). 
(20) Not able to liquefy sodium pectate gel, although able to grow on this medium.

(21) Able to grow in skim milk; litmus and methylene blue reduced.

(22) Indole negative (in peptone or tryptophan medium).

(23) Methyl red positive.

(24) Voges-Proskauer negative, but fluorescin formation masked colour reactions.

(25) Tolerated an alkaline $\mathrm{pH}$ value, i.e. survived more than 6 months at room temperature in $\mathrm{YE}$ broth at $\mathrm{pH} c .8 \cdot 6$.

(26) Non-viable after 3 weeks at room temperature on galactose + ammonium + inorganic salts medium initially at $\mathbf{p H ~} 7 \cdot 0$.

It is concluded that, under the specified test conditions, the characteristics 1-26 above describe a fairly clearly defined group of organisms. Some of the characters have been used before in the description or definition of the genus Pseudomonas (see Migula, 1894; Chester, 1901; Tanner, 1918; Clara 1934; Seleen \& Stark, 1943; Burkholder \& Starr, 1948; Dr S. T. Cowan, personal communication; Topley \& Wilson's Principles, 1955; Bergey's Manual, 1957).

The taxonomic rank accorded to any group of bacterial isolates with certain characteristics in common reflects personal opinion, and the characters cited above form a basis for an extended description and definition of the genus Pseudomonas. Others may show that some of the criteria are not suitable for the genus definition; e.g. oxalate-decomposing pseudomonads have been described (Bhat \& Barker, 1948; Khambata \& Bhat, 1953; Jayasuriya, 1955), but Pseudomonas oxaliticus Khambata \& Bhat and the OD isolates of Jayasuriya show unusual properties for pseudomonads. Similarly, there are reports of cellulose-decomposing pseudomonads (Steel \& Walker, 1957; Goto \& Okabe, 1958); of diastatic strains (Lacey, 1932); of salicin-utilizers (Clara, 1934); of pectin decomposers, e.g.P. prunicola (Mills, 1949), some strains of $\boldsymbol{P}$. marginalis, $P$. syringae and $P$. medicaginis var. phaseolicola (Smith, 1958). Because of such reports, these criteria should perhaps be withheld from the genus definition, but they may be useful in the separation of species. Before any of the above criteria are discarded we should be sure that the strains which make us doubt the validity of the criteria are pseudomonads and possess most of the group characters cited. The study by Sneath $(1956 a, b)$ greatly facilitates the differentiation of the closely related Chromobacterium genus. Another related genus, Acetobacter, also merits consideration when attempting to define Pseudomonas, particularly because of the report by Steel \& Walker (1957) that two strains of $A$. acetigenum and one of $A$. xylinum gave rise to 26 celluloseless mutants which were identified as $\boldsymbol{P}$. geniculata. Finally Vibrio must be considered when suggesting definitions for Pseudomonas.

It may be asked whether the group of 165 isolates defined above may justifiably be subdivided. A further 43 characters were not common to all isolates. The numbers of isolates which showed positive reactions in the 43 tests is shown in Fig. 1. Many of these characters have been used for the characterization of various species of Pseudomonas, e.g. Bergey's Manual (1957), Chester (1901), Elliott (1951), Dowson (1957). The tests were applied to the 


\section{Pseudomonas fluorescens}

present collection with the hope that clearly defined subgroups (species?) would be revealed. Eventually this was not found to be the case. Figure 1, which summarizes the results, does not reveal the fact that there was no correlation between any two of the $\mathbf{4 3}$ characters mentioned; the negative isolates in one

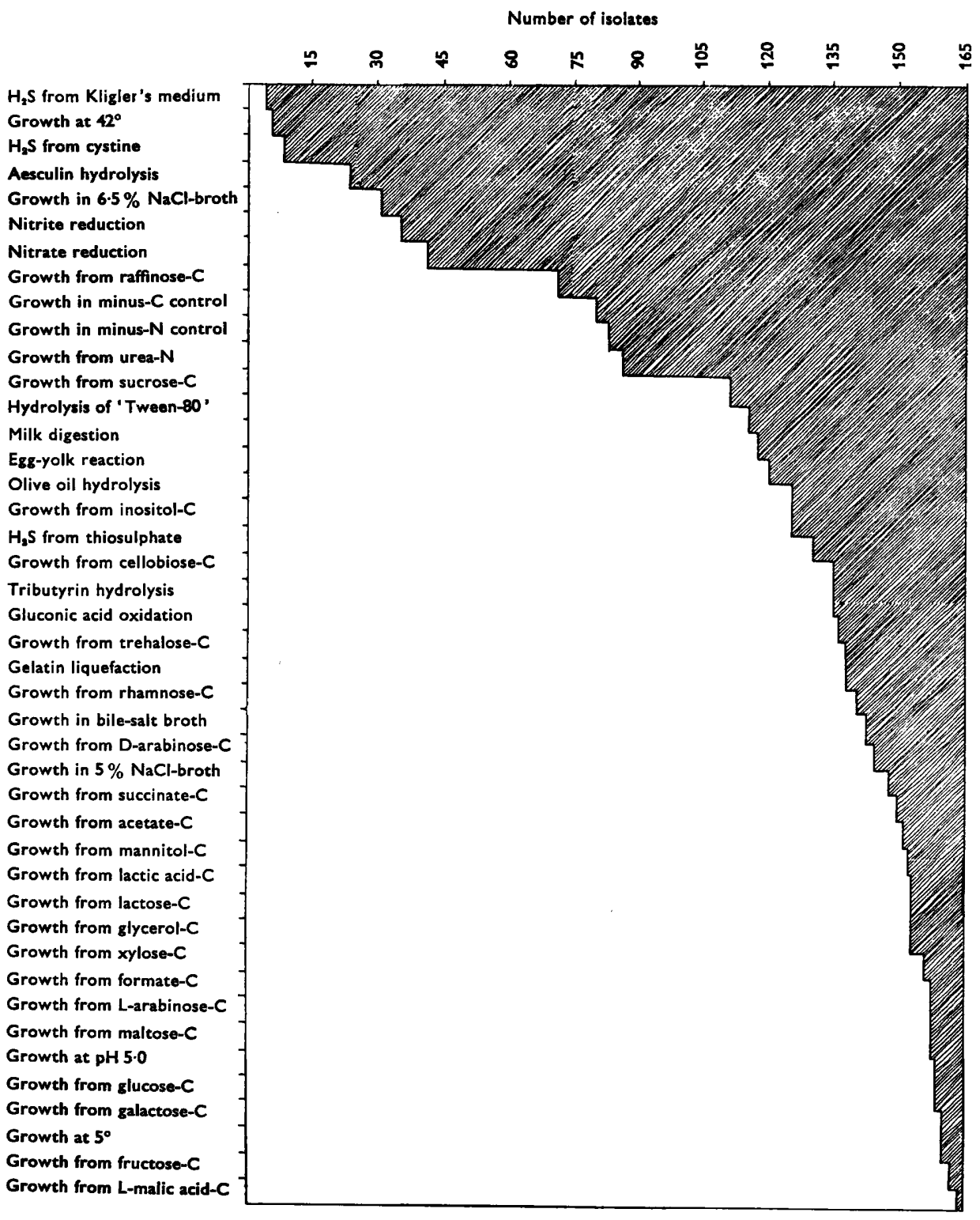

Fig. 1. Histogram showing the number of positive and negative test results when 165 isolates of Pseudomonas were tested for 43 characters. These 43 characters were chosen because they were not common to the whole group of 165 isolates; this group was definable on the basis of 26 other characters. See text for details of all the test characters used. Hatched areas indicate negative results; clear areas indicate positive test results. 


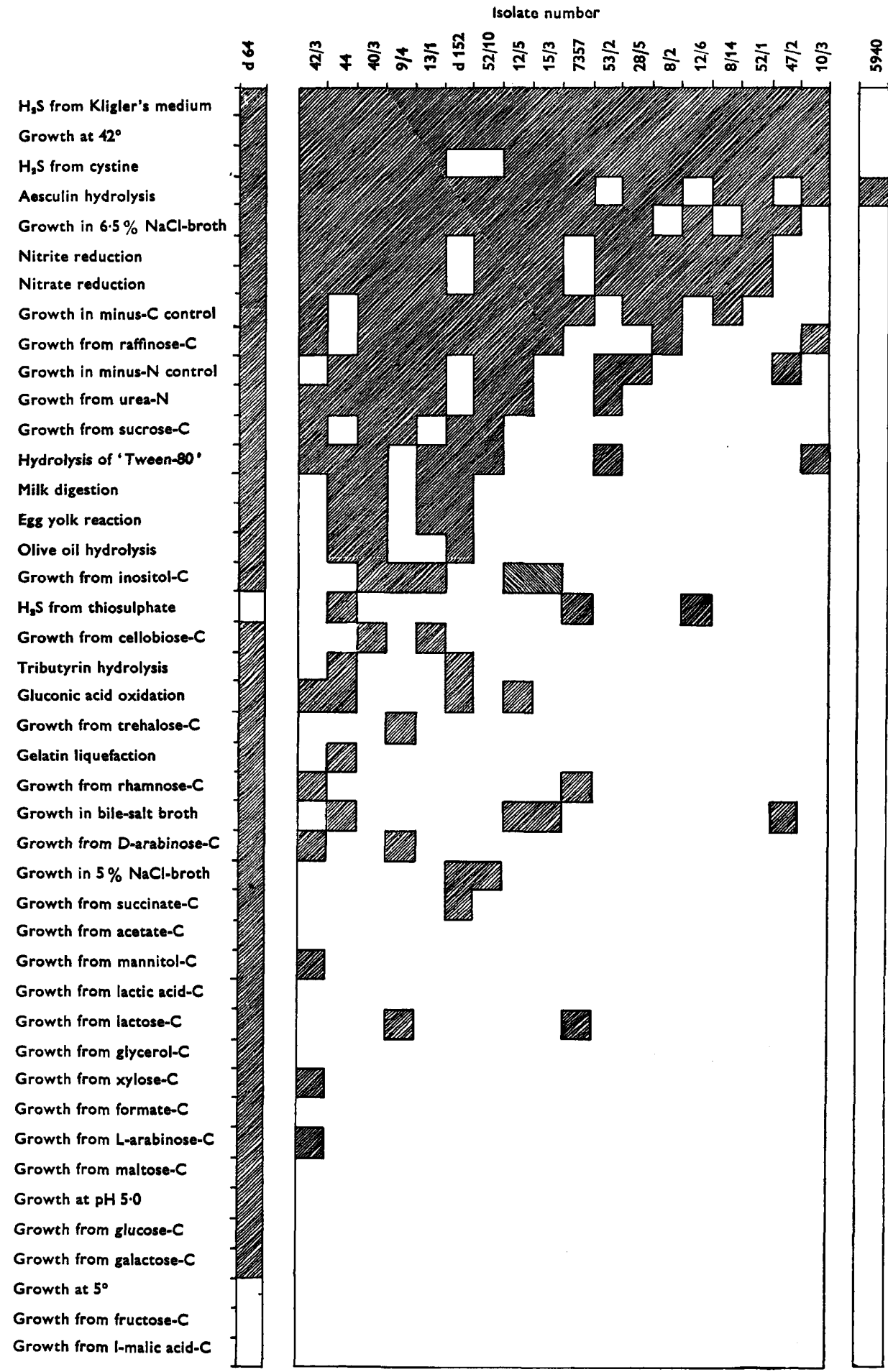

Fig. 2. Illustration of the range of variation shown by a random selection of $c .10 \cdot 0 \%$ of the isolates of the pseudomonad collection concerning 43 differential test characters. Isolates no. 5940 (P. fluorescens, NCTC 5940) and d64 (P. savastanoi from Dr W. J. Dowson) are also included for comparison: no. 5940 was the most reactive isolate of the whole collection and $\mathrm{d} 64$ the most non-reactive. For details of test characters, see text. Hatched areas indicate negative results; clear areas indicate positive test results. 


\section{Pseudomonas fluorescens}

column were not identical with those in any other. One isolate gave positive reactions in 42 of the 43 characters, and one was negative for 39 characters: the remaining isolates could be arranged between these extremes in an order of a gradually increasing number of negative characters. Among 58 isolates there were 21 small groups of identical isolates, but the largest number in any group was 5; the remaining 107 isolates each had a different combination of the 43 characters. A similar situation emerged in the taxonomic study of aquatic fluorescent pseudomonads by Tanner (1918); he suggested the use of more

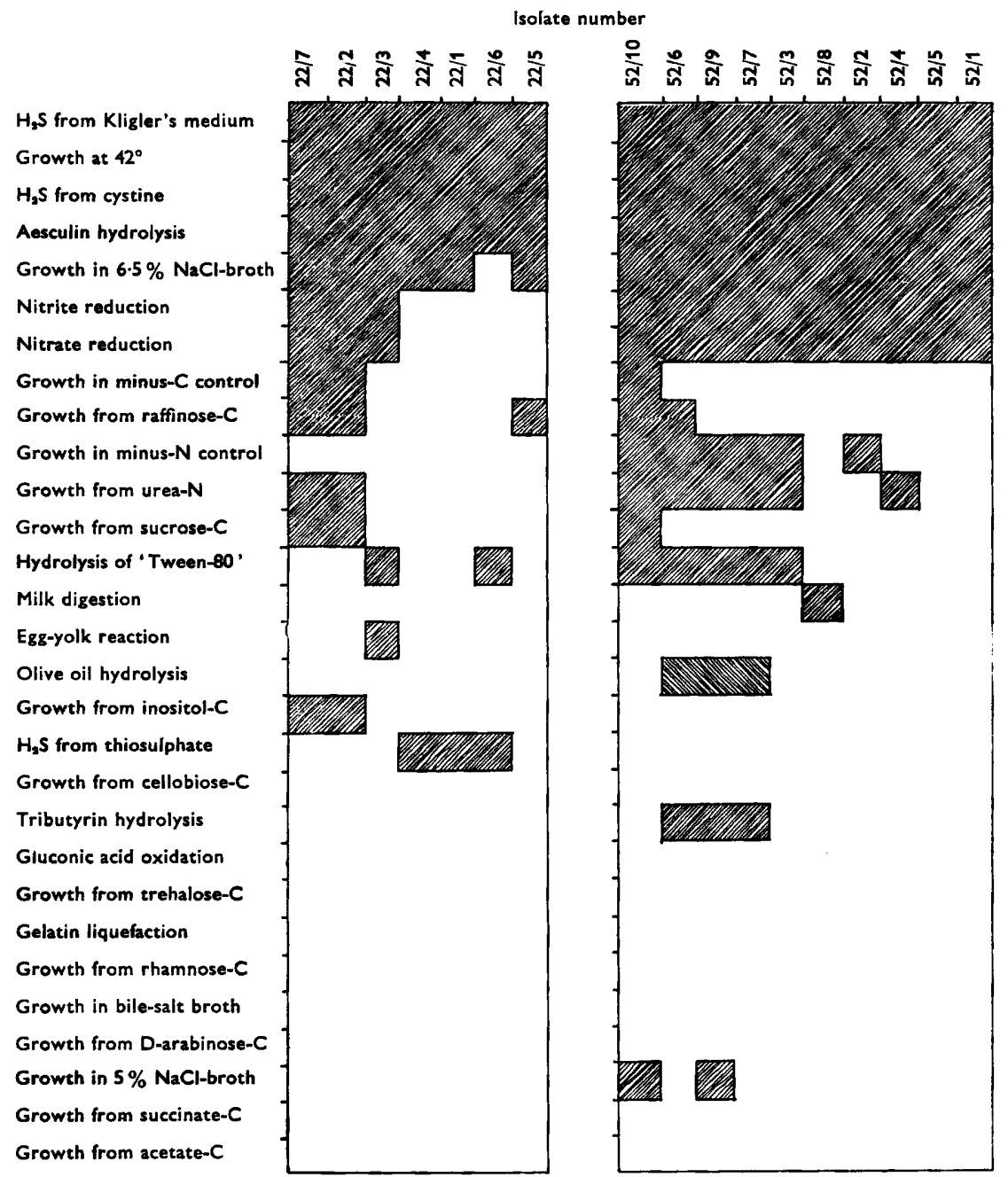

Fig. 3. To show the range of vuriation concerning 29 test characters, exhibited by the 10 pseudomonad isolates of the no. 52 series; each isolate was originally obtained from a single fluorescent pigment-producing colony, and all 10 isolates were picked from one plate of nutrient medium which had been streaked with one $4 \mathrm{~mm}$. loopful of river water. Series no. 22 similarly shows the properties of 7 isolates all originally derived from $1 \mathrm{ml}$. raw milk. See text for details of the test characters. Hatched areas indicate negative results; clear areas indicate positive test results. 
refined experimental techniques as the remedy, but perhaps these were already too refined. His use of the 'Group Number' system as a device to express equal emphasis on all the diagnostic characters used is noteworthy. The same approach has been taken here (see Sneath, 1957 $a, b$, for the argument concerning the validity of this Adansonian approach).

Full tables of the results obtained in this work, involving 165 isolates and 43 characters cannot be given here; the complete data are available in this Department. All the data have been arranged and sorted in many ways as objectively as possible, giving equal weight to every character, to see whether there were any larger groups with at least two correlated characteristics in common. None could be found. To convey the great range of variation among the isolates Fig. 2 is given as a sample of the picture shown by c. $10.0 \%$ of the isolates, randomly selected.

\section{Table 5. Showing the eight variable properties exhibited by the five isolates of Pseudomonas aeruginosa tested}

The characters of two $\boldsymbol{P}$. fluorescens-type isolates are given for comparison. Thirty-seven other characters were positive for all seven isolates (see text). +indicates a positive result; - indicates a negative result.

\begin{tabular}{|c|c|c|c|c|c|c|c|c|}
\hline Isolate & $\begin{array}{l}\text { Pyocyanine } \\
\text { production }\end{array}$ & $\begin{array}{l}\text { Fluorescin } \\
\text { production }\end{array}$ & $\begin{array}{l}\text { Growth } \\
\text { at } 42^{\circ}\end{array}$ & $\begin{array}{c}\mathbf{H}_{\mathbf{2}} \mathbf{S} \\
\text { from } \\
\text { Kligler's } \\
\text { medium }\end{array}$ & $\begin{array}{c}\mathrm{H}_{\mathbf{2}} \mathrm{S} \\
\text { from } \\
\text { cystine }\end{array}$ & $\begin{array}{l}\text { Aesculin } \\
\text { hydrolysis }\end{array}$ & $\begin{array}{c}\mathbf{H}_{\mathbf{2}} \mathbf{S} \text { from } \\
\text { thiosulphate }\end{array}$ & $\begin{array}{l}\text { Growth } \\
\text { at } 5^{\circ}\end{array}$ \\
\hline 5940 & - & + & + & + & + & - & + & + \\
\hline 20 & + & + & + & + & + & - & - & - \\
\hline 21 & - & + & + & + & + & - & - & - \\
\hline $24 / 2$ & + & + & + & + & + & - & - & - \\
\hline $24 / 1$ & + & + & + & + & - & - & - & - \\
\hline $36 / 4$ & - & + & - & - & - & - & + & + \\
\hline $8 / 11$ & - & + & - & - & - & - & - & + \\
\hline
\end{tabular}

Another illustration of the variation exhibited by the isolates with regard to these 43 properties is given in Fig. 3. Here the 10 isolates of the no. 52 series (which were all orginally isolated as separate fluorescent pigmentproducing colonies on one plate of YE agar which had been streaked with one loopful of River Kennet water) are shown. Series no. 22, with seven isolates similarly derived from $1 \mathrm{ml}$. of a raw milk sample, is also shown. It is therefore concluded that the $\mathbf{4 3}$ properties are not useful for the definition of subgroups because of their complete lack of correlation with each other. Furthermore, some of these properties are unstable under certain conditions and when adequately tested it seems probable that many more would be found to be unstable. Further conclusions which emerged from an examination of the complete data are as follows.

(1) There was a group of 5 isolates able to grow at $42^{\circ}$ and to produce hydrogen sulphide on Kligler's medium. These were positive in all the other 41 characters, with few exceptions (see Table 5). In many respects this group conforms with the revised characterization of $\boldsymbol{P}$ seudomonas aeruginosa (Haynes, 1951; Gaby, 1955). Too few of these isolates of this accepted species have been examined here to warrant further comment, but the properties of isolates 8/11 
and $36 / 4$ (in Table 5 ) indicate the close overall similarity of some $\boldsymbol{P}$. fluorescenstype isolates when a total of 45 characters is considered. Liu (1952) claimed that $\boldsymbol{P}$. aeruginosa showed a definite biochemical pattern of carbohydrate utilization; this pattern was given by many $\boldsymbol{P}$. fluorescens-type isolates of the present collection. Brown (1957) concluded that there were no obvious distinctions between $\boldsymbol{P}$. aeruginosa and psychrophilic $\boldsymbol{P}$. fuorescens-type organisms, but he found that the latter were able to multiply much sooner over nearly the whole temperature range in which growth of both species occurred, suggesting the greater adaptability of the psychrophil in a new and more difficult environment. Furthermore, the psychrophil showed a much more vigorous glucose-oxidizing ability over a wider range of temperature, and a greater acid tolerance. This is in keeping with my view that $P$. aeruginosa is more likely to be derived from a less specialized ' wild type'such as $\boldsymbol{P}$. fluorescens, rather than the reverse.

(2) Isolate d 289 (WJD, Pseudomonas marginalis) was identical with isolates 47/1 and 47/4 (from a vase of tap water containing a Colchicum flower), except that the latter two were unable to grow in bile salt broth. Isolate $\mathrm{d} 52$ (WJD; P. medicaginis var. phaseolicola) was identical with isolates 52/1 and 52/5 (from River Kennet water). Isolate d 263 (WJD; $P$. angulata) was identical with isolate $7 / 3$ (from a pond) and isolates $8 / 2$ and $8 / 15$ (from human plasma); all these had the same 8 negative characters. Isolate $\mathrm{d} 244$ (WJD; $P$. barkeri) was identical with isolate $25 / 1$ (from the air of a veterinary laboratory) and these two had the same 12 negative characters. This suggests either that phytopathogens may be found in a wide variety of natural habitats, or that phytopathogenicity is not associated with any particular metabolic or cultural pattern so far investigated. Phytopathogenicity tests on all these isolates might profitably be attempted; Clara (1934) found that $\boldsymbol{P}$. fluorescens caused mild disease symptoms on Kieffer pears; Stapp (1955) reported that a strain of $\boldsymbol{P}$. aeruginosa was pathogenic to potato tubers; $\boldsymbol{P}$. polycolor (Elrod \& Braun, 1942) is a well-known facultative plant and animal pathogen. The close similarity between phytopathogenic and saprophytic pseudomonads, such as described by St John Brooks, Nain \& Rhodes (1925), and by Friedman (1953) who used physiological and serological criteria, is thus accidentally confirmed.

(3) Of the remaining named phytopathogens 11 had between 23 and 39 negative characters (of the $\mathbf{4 3}$ under consideration). They occupied positions almost exclusively at the lower end of a table arranged to show isolates with an increasing number of negative characters, suggesting a relationship between phytopathogenicity and a decreased ability to withstand inimical agents such as sodium chloride, bile salts or acids. Also, fewer carbon sources were utilized, and 7 of these isolates did not grow with glucose as carbon source; nearly all the biochemical reactions were negative too, and the rate of growth on complex nutrient medium was also slower. This perhaps again indicates decreased physiological adaptability, compared with the 'wild-type' $\boldsymbol{P}$. fluorescens, as being concomitant with effective pathogenicity.

(4) When the named isolates of this collection (those obtained from diseased plant material and the $\boldsymbol{P}$. aeruginosa group) are omitted, the following further 
characterization applied to the remaining group of 134 isolates from saprophytic soil- and water-type environments (initially they produced fluorescin):

(a) Did not produce hydrogen sulphide from Kligler's medium. (b) Would not grow at $42^{\circ}$ or $37^{\circ}$. (c) Would grow well at $5^{\circ}$. (d) Would grow in YE broth initially at $\mathrm{pH} 5 \cdot 0$. (e) Would utilize glucose, galactose, fructose, maltose, 1-malic acid and lactic acid when these were supplied as added carbon sources in a Koser-type defined basal medium.

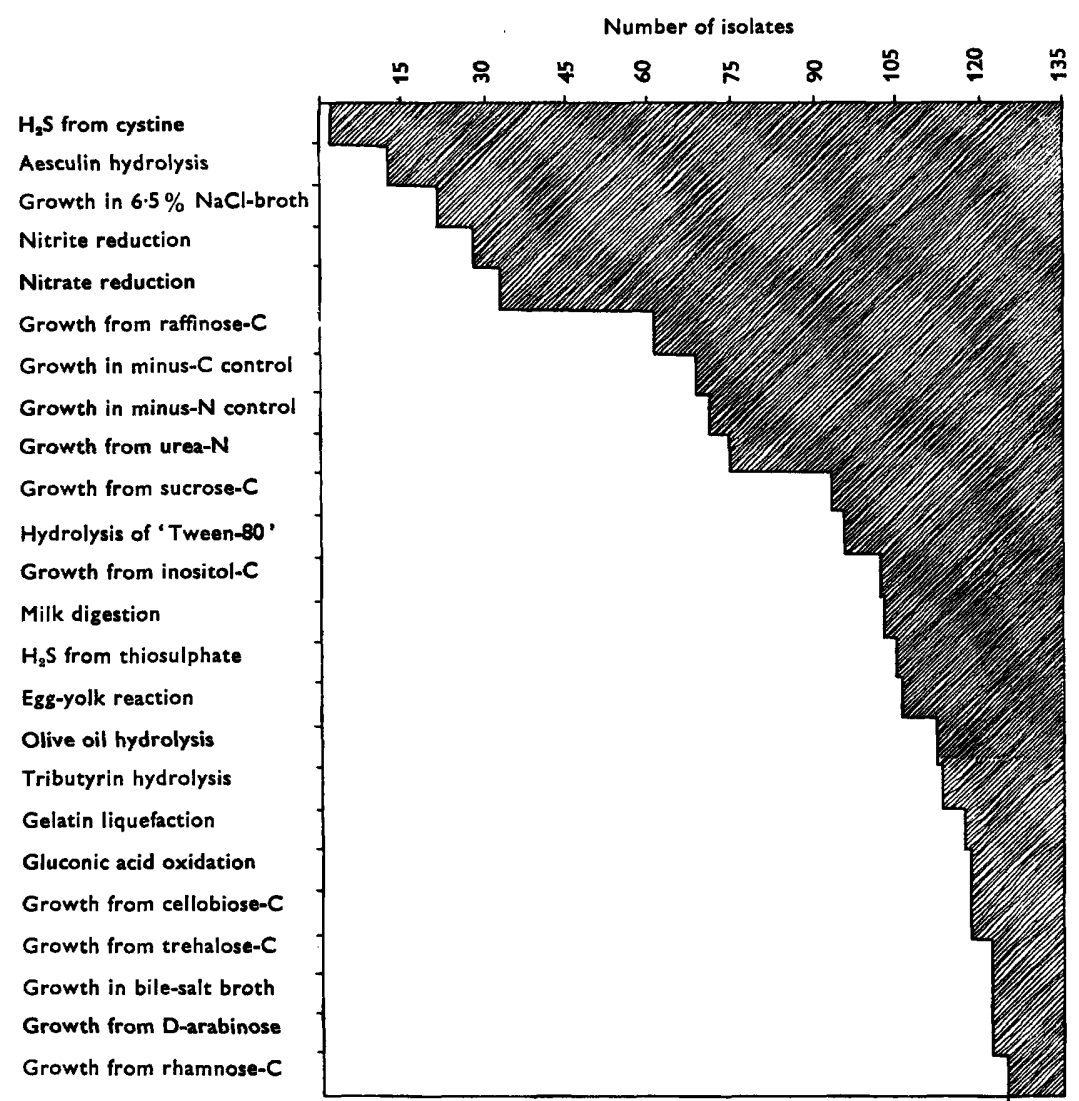

Fig. 4. Histogram showing the number of positive and negative test results obtained when 134 Pseudomonas isolates, all soil and water types initially producing fluorescin, were examined by means of 24 differential test characters. See text for full details of tests. Hatched areas indicate negative results; clear areas indicate positive test results.

In a further 9 tests only the following isolates (bracketed) showed a negative reaction: glycerol $(43 / 1)$, succinate (10/1), L-arabinose $(42 / 2,42 / 3)$, formate $(10 / 1,27 / 3)$, acetate $(10 / 1,27 / 3)$, lactose $(9 / 4,13 / 4)$, xylose $(9 / 2,42 / 3)$, mannitol $(42 / 2,42 / 3,43 / 4)$, ability to grow in YE broth $+5.0 \% \mathrm{NaCl}(5 / 5,8 / 6$, $42 / 2,52 / 9,52 / 10)$. The isolate numbers are given to show that these nonconformities were not correlated; they were shown by only 13 different isolates.

The numbers of the 134 fluorescent isolates which showed positive reactions 
in the remaining 24 tests are given in Fig. 4. No correlation of any of the characters was evident and further subdivision of this group is thus not considered to be practicable or justified, because, for example, the same 122 isolates were not positive in the D-arabinose, trehalose and bile salt broth tests.

Thus an accurate description of commonly occurring pseudomonads can be made. From the full data mathematically inclined taxonomists might well derive further conclusions, but I put forward, from the work described here, the following description of the genus Pseudomonas, and by using further characters give a revised definition of Pseudomonas fuorescens Migula (see also the Int. Bull. Bact. Nomen. \& Taxon. 1951, 1952). This description is :

Genus Pseudomonas Migula, 1894

Gram-negative non-endospore-forming rods with size range $\mathbf{1} \cdot \mathbf{0 - 3 . 0} \times \mathbf{0 . 5}$ $0.7 \mu$. Able to grow aerobically within $48 \mathrm{hr}$. at $25^{\circ}$ on yeast extract + peptone media (initial $\mathrm{pH} \mathrm{7 \cdot 2)}$ with a sodium chloride concentration up to $3.0 \%$. Catalase-positive. Produce some free ammonia when grown in peptone water medium, and after 7 days at $25^{\circ}$ the medium is alkaline (c. $\mathrm{pH} \mathrm{8.6)}$. Polar flagella (1-10) and exocellular slime present. Colonial appearance on complex yeast extract + peptone or nutrient media very variable. Obligate aerobes; no growth in glucose + peptone water under strictly anaerobic conditions. Able to grow at $12-3^{\circ}$; no clear-cut temperature optima. Able to grow in complex nutrient media (initially $\mathrm{pH} 5 \cdot 5$ ) but not able to grow when initial $\mathrm{pH}$ value is less than 4.5. Resistant to the pteridine derivative $0 / 129$. Able to use ammonia- $\mathbf{N}$ when it is supplied as the sole source of added nitrogen in a suitable inorganic salts basal medium. Able to grow in Koser's citrate medium or in a similar basal medium with the citrate replaced by sorbitol. No factor in Difco yeast extract stimulates growth in the simple chemically defined media used here. No significant growth (i.e. more than in control medium without added carbon source) when dulcitol is supplied as the sole added carbon source. Able to grow on gelatin medium (no peptone) and on potato slopes. Able to grow in skim milk with reduction of litmus or methylene blue. Indole negative. Methyl red positive. Voges-Proskauer negative (but fluorescin may mask colour reaction). Tolerate an alkaline $\mathrm{pH}$ value, i.e. survive more than 6 months at room temperature in $\mathrm{YE}$ broth with a $\mathrm{pH}$ value 8.5 at 14 days. Non-viable after 3 weeks at room temperature on ammonium + inorganic salts + galactose medium (initially $\mathrm{pH} \mathrm{7 \cdot 0}$ ).

\section{Species Pseudomonas fluorescens Migula, 1894}

This species possesses all the properties of the genus as described above, together with the following characters: will not grow at $42^{\circ}$ or $37^{\circ}$; will grow well at $5^{\circ}$. Will grow in complex nutrient media of $\mathrm{pH} \mathrm{5.0.} \mathrm{Grows,} \mathrm{but} \mathrm{does}$ not produce hydrogen sulphide, on Kligler's medium. Will utilize glucose, galactose, fructose, maltose, l-malic acid or lactic acid when these are supplied as the sole added carbon source in a Koser-type inorganic salt medium.

The following properties may be positive or negative (the number in brackets refers to the $\%$ of isolates in this collection which showed a positive 
reaction): utilization of glycerol (99), succinate (99), L-arabinose (98), formate $(98)$, acetate $(98)$, lactose $(98)$, xylose (98), mannitol (98), rhamnose (93), D-arabinose (91), trehalose (91), cellobiose (88), inositol (75), sucrose (70), raffinose (46), when these substrates are supplied as the sole added carbon source in ammonium + inorganic salts medium; growth in peptone yeastextract $+5.0 \%(\mathrm{w} / \mathrm{v}) \mathrm{NaCl}$ medium (96); ability to grow in MacConkey's bile salt broth (91); production of 2-keto-D-gluconate acid from D-gluconate (88); liquefaction of gelatin (87); production of an egg-yolk reaction (79); production of hydrogen sulphide from thiosulphate (78); digestion of milk protein (76); hydrolysis of Tween 80 (72); production of definite turbidity in an inorganic salts medium without an added nitrogen (53), or added carbon source (52); reduction of nitrate (25); reduction of nitrite (21); growth in yeast-extract + peptone $+6.5 \%(\mathrm{w} / \mathrm{v}) \mathrm{NaCl}$ medium (16); hydrolysis of aesculin (10); production of hydrogen sulphide from cystine (1).

Note. The production of fluorescent pigment (or indeed any pigment) is not used in the above definitions because it is generally admitted that the property is unstable and dependent on the nature of the medium for its manifestation (see Seleen \& Stark, 1943, for review). Moreover, greenish yellow fluorescent pigment production by non-pseudomonads has been recorded, e.g. by Bacillus subtilis (Shank, Chmura \& Silliker, 1958).

The description of Pseudomonas fluorescens in the latest (7th) edition of Bergey's Manual (1957) differs from the above in many details. Also, if the definition of $\boldsymbol{P}$. fluorescens suggested here be acceptable, many of the Pseudomonas species listed in the Bergey's Manual (1957) appear to be unjustified. In the absence of adequate data concerning some organisms, judgement is postponed, but the writer feels that the following species descriptions agree well with the $\boldsymbol{P}$. fluorescens described above, namely, $\boldsymbol{P}$. schuylkilliensis, geniculata, septica, incognita, mildenbergii, convexa, eisenbergii, cohaerens, denitrificans. The following list of species seems to possess only minor differences: $\boldsymbol{P}$. syncyanea, tetraolens, rugosa, putrefaciens, striata, ovalis, mephitica, mira, putida. Gaby (1955) thought that $P$. mildenbergii and $P$. ovalis, and $P$. fuorescens and $P$. putrefaciens were indistinguishable pairs. Clara (1934) found that $\boldsymbol{P}$. putida and $\boldsymbol{P}$. fluorescens differed only in minor characters. The above suggested description for $\boldsymbol{P}$. fluorescens agrees much more closely with the $\boldsymbol{P}$. fluorescens as described by Clara than with that of Bergey's Manual. Seleen \& Stark (1943) also showed a close similarity between $P$. denitrificans, putida, ovalis and convexa. Ideally, comparison of named cultures (when available) and freshly isolated cultures of all these species, using standardized techniques, is necessary so that some of the 'taxonomic problems' outlined by Gaby (1955) concerning the identification of Pseudomonas species may be clarified. The literature concerning the use of serology for Pseudomonas differentiation was reviewed by Munoz, Scherago \& Weaver (1949); their own findings were encouraging in that their three strains of $\boldsymbol{P}$. fluorescens were serologically similar (contrast serological heterogeneity of $\boldsymbol{P}$. fluorescens reported by Friedman, 1953), but they concluded that $\boldsymbol{P}$. fluorescens, mildenbergii, ovalis and putida showed no serological relationships; they were quite 
distinct on the basis of flagellar antigens. Thus is posed a fundamental problem of bacterial classification, i.e. the status of a bacterial species, and whether this taxonomic rank should be assigned to organisms which may be distinguished only serologically (Kauffman, 1959).

A neotype isolate of Pseudomonas fluorescens has been selected (no. 2/85, see Fig. 2 here) and deposited in the National Collection of Type Cultures, Colindale, London, England (no. 10,038) and in the American Type Culture Collection (no. 13,525).

The author wishes to thank Dr W. J. Dowson for the gift of 19 cultures of phytopathogenic Pseudomonas spp. ; the National Collection of Type Cultures for 5 Pseudomonas and 5 Vibrio spp. cultures; Dr M. Kogut for the Pseudomonas strain KB 1; Mr W. Hodgkiss for Vibrio icthyodermis PL 1; Imperial Chemical Industries, Ltd. (Manchester) for the gift of Alcian Blue 8 G. 150; Dr H. O. J. Collier for the vibriostatic pteridine compound $\mathrm{O} / 129$ and the phosphate derivative of it. To Professor B. C. J. G. Knight and Dr S. T. Cowan very sincere thanks are expressed for their interest and constructive criticism during the preparation of this paper.

This paper is based on work recorded in a Ph.D thesis for Reading University (Rhodes, 1956).

\section{REFERENCES}

Anderson, G. R. (1955). Nitrogen fixation by Pseudomonas-like soil bacteria. J. Bact. 70, 129.

Ayers, S. H., Rupp, P. \& Johnson, W. T. (1919). A study of the alkali-forming bacteria found in milk. Bull. U.S. Dep. Agric. no. 782.

Bergey's Manual of Determinative Bacteriology (1957). 7th ed. Edited by R. S. Breed, E. G. D. Murray and N. R. Smith. London: Baillière, Tindall and Cox (5th ed. 1939: 6th ed. 1948; different editors for these earlier editions).

Bhat, J. V. \& Barker, H. A. (1948). Studies of a new oxalate-decomposing bacterium, Vibrio oxaliticus. J. Bact. 55, 359.

Brough, F. (1950). Micro-technique for nitrate reduction. J. Bact. 60, 365.

Brown, A. D. (1957). Some general properties of a psychrophilic pseudomonad; the effects of temperature on some of these properties and the utilization of glucose by this organism and Pseudomonas aeruginosa. J. gen. Microbiol. 17, 670.

Burkeolder, W. H. \& STaRr, M. P. (1948). The generic and specific characters of phytopathogenic species of Pseudomonas and Xanthomonas. Phytopathology, 38, 494 .

Chester, F. D. (1901). A Manual of Determinative Bacteriology, 1st ed. New York: Macmillan Co.

Christensen, W. B. (1946). Urea decomposition as a means of differentiating Proteus and Paracolon organisms from each other and from Salmonella and Shigella types. J. Bact. 52, 461.

Clara, F. M. (1934). A Comparative Study of the Green-Fluorescent Bacterial Plant Pathogens. Cornell Univ. Agric. Exp. Stat. Mem. no. 159.

Colnins, M. A. \& HAMmer, B. W. (1934). Types of lipolysis brought about by bacteria as shown by Nile-blue sulphate. J. Bact. 27,487 .

Cowan, S. T. (1953). Fermentations: biochemical micromethods for bacteriology. J. gen. Microbiol. 8, 391.

DE TURK, W. E. (1955). The adaptive formation of urease by washed suspensions of Pseudomonas aeruginosa. J. Bact. 70, 187.

Dowson, W. J. (1949). Manual of Bacterial Plant Diseases, 1st ed. London: A. and C. Black.

Dowson, W. J. (1957). Plant Diseases Due to Bacteria, 2nd ed. Cambridge: The University Press. 
EAGon, R. G. (1956). Studies on polysaccharide formation by Pseudomonas fluorescens. Canad. J. Microbiol. 2, 673.

Elliotr, C. (1951). Manual of Bacterial Plant Pathogens, 2nd ed. Waltham, Mass.: Chronica Botanica Co.

Elrod, R. P. \& Braun, A. C. (1942). Pseudomonas aeruginosa: its role as a plant pathogen. J. Bact. 44, 633.

Englesberg, E. \& Stanier, R. Y. (1949). The relationship between growth and mutation in Pseudomonas fluorescens. J. Bact. 58, 171.

Erikson, D. (1945). Certain aspects of resistance of plum trees to bacterial canker. I. Some biochemical characteristics of Pseudomonas mors-prunorum and related phytopathogenic bacteria. Ann. appl. Biol. 32, 44.

Fernley, H. N. \& Evans, W. C. (1958). Oxidative metabolism of polycyclic hydrocarbons by soil pseudomonads. Nature, Lond. 182, 373.

Fouad, M. T. A. \& Richards, T. (1953). The use of glucose inorganic salts media in the classification of the coli-aerogenes bacteria. I. The methyl red and VogesProskauer reactions. Proc. Soc. appl. Bact. 16, 35.

Frazrer, W. C. (1926). A method for the detection of changes in gelatin due to bacteria. J. infect. Dis. 39, 302.

Friedman, B. A. (1953). Serological tests with some phytopathogenic species of Pseudomonas. Phytopathology, 43, 412.

Fuchs, A. (1956). Synthesis of levan by pseudomonads. Nature, Lond. 178, 921.

GABY, W. L. (1955). Taxonomic problems relating to the identification of species within the genus Pseudomonas. Int. Bull. Bact. Nomen. \& Taxon. 5, 153.

GABY, W. L. \& FREE, E. (1953). Occurrence and identification of non-pigmented strains of Pseudomonas aeruginosa in the clinical laboratory. J. Bact. 65, 746.

Gaby, W. L. \& Hadley, C. (1957). Practical laboratory test for the identification of Pseudomonas aeruginosa. J. Bact. 74, 356.

Garvie, E. I. (1955). The growth of Escherichia coli in buffer substrate and distilled water. J. Bact. 69, 393.

Goldman, M. L. \& Rayman, M. M. (1952). Hydrolysis of fats by bacteria of the Pseudomonas genus. Food Res. 17, 326.

Goтo, M. \& OKaвE, N. (1958). Cellulolytic activity of phytopathogenic bacteria. Nature, Lond. 182, 1516.

Greuell, E. H. M. \& Sierra, G. (1957). Studies on bacterial esterases. Part II. Paper-electrophoresis of the esterases of Pseudomonas aeruginosa. Leeurvenhoek ned. Tijdschr. 23, 273.

Hamdy, M. K., Sherrer, E. L., Randles, C. I., Weiser, H. H. \& Sheets, W. D. (1956). Some characteristics of a phenol-oxidizing Pseudomonas. Appl. Microbiol. 4, 71.

Haynes, W. C. (1951). Pseudomonas aeruginosa-its characterization and identification. J. gen. Microbiol. 5, 939.

Hormaeche, E. \& Munilla, M. (1957). Biochemical tests for the differentiation of Klebsiella and Cloaca. Int. Bull. bact. Nomen. \& Taxon. 7, 1.

Hugh, R. \& LeIfson, E. (1953). The taxonomic significance of fermentative versus oxidative metabolism of carbohydrates by various Gram-negative bacteria. J. Bact. 66, 24.

Int. Bull. Bact. Nomen. \& Taxon. (1951). Status of Pseudomonas Migula 1894 as a generic name, and of Pseudomonas aeruginosa (Schröter) Migula 1900 as type species. Preliminary statement, File no. 7, 1, 41.

Int. Bull. Bact. Nomen. \& Taxon. (1952). Conservation of the generic name Pseudomonas Migula 1894 and designation of Pseudomonas aeruginosa (Schröter) Migula 1900 as type species. Opinion no. 5. Judicial Commission, 2, 121.

J ANNASCH, H. W. (1958). Experimental studies of nitrogen concentrations limiting the growth of Pseudomonas fluorescens and Bacillus subtilis in natural waters. Bact. Proc. p. 55. 


\section{Pseudomonas fluorescens}

JAYASURIYA, G. C. N. (1955). The isolation and characteristics of an oxalatedecomposing organism. J. gen. Microbiol. 12, 419.

Jensen, H. L. (1951). Notes on the biology of Azotobacter. Proc. Soc. appl. Bact. 14, 89.

Jones, A. \& Richards, T. (1952). Night Blue and Victoria Blue as indicators in lipolysis media. Proc. Soc. appl. Bact. 15, 82.

KatzNelson, H. (1955). The metabolism of phytopathogenic bacteria. I. comparative studies on the metabolism of representative species. J. Bact. 70, 469 .

KAUFFMAN, F. (1959). On the principles of classification and nomenclature of the Enterobacteriaceae. Int. Bull. Bact. Nomen. Tax. 9, 1.

Khambata, S. R. \& Bhat, J. V. (1953). Studies on a new oxalate-decomposing bacterium, Pseudomonas oxaliticus. J. Bact. 66, 505.

KLAusmeier, R. E. \& Strawinski, R. J. (1957). Microbial oxidation of naphthalene. I. Factors concerning salicylate accumulation. J. Bact. 73, 461 .

Kuteneberger-Nobel, E. (1948). Capsules and mucoid envelopes of bacteria. J. Hyg., Camb. 46, 345.

KLIENEBERGER-NobeL, E. (1950). Methods for the study of the cytology of bacteria and pleuropneumonia-like organisms. Quart. J. micr. Sci. 91, 340.

Kluyver, A. J. \& Niel, C. B. van (1936). Prospects for a natural system of classification of bacteria. Zbl. Bakt. (II. Abt. Bd.), 94, 369.

Knight, B. C. J. G. \& Proom, H. (1950). A comparative survey of the nutrition and physiology of mesophilic species in the genus Bacillus. J. gen. Microbiol. 4, 508.

Koser, S. A. (1923). Utilisation of the salts of organic acids by the colon-aerogenes group. J. Bact. 8, 493.

LACEY, M. S. (1932). Studies in bacteriosis. XIX. Researches on the group of greenfluorescent bacteria. II. On some plant diseases caused by such. Ann. appl. Biol. 19, 190.

Leathen, W. W. \& Braley, S. A. (1955). Interpretations of reactions in acid thiosulphate media. J. Bact. 69, 481.

LEIFson, E. (1951). Staining, shape and arrangement of bacterial flagella. J. Bact. 62,377 .

Lewis, I. M. (1930). The inhibition of Phytomonas malvaceara in culture media containing sugars. J. Bact. 19, 423.

LIU, P. (1952). Utilization of carbohydrates by Pseudomonas aeruginosa. J. Bact. 64, 773.

LIU, P. V. (1957). Survey of haemolysin production among species of pseudomonads. J. Bact. 74, 718.

Lockwood, L. B. \& Nelson, G. E. N. (1946). The oxidation of pentoses by Pseudomonas. J. Bact. 52, 581.

Mackie, T. J. \& McCartney, J. E. (1953). Handbook of Practical Bacteriology, 9th ed. Edinburgh: Livingstone.

Manual of Microbiological Methods (1957). Ed. Committee on Bacteriological Technic, Society of American Bacteriologists. London: McGraw-Hill.

Martin, W. R. \& Foster, J. W. (1957). Adaption patterns in the utilization of the stereoisomers of tartaric acid by a pseudomonad. J. Bact. 73, 683 .

Migula, W. (1894). Ueber ein neues System der Bakterien. Arb. bakt. Inst. Karlsruhe, 1, 235.

Mrres, E. M. \& Mrues, A. A. (1951). The identity of Proteus hydrophilus.Bergey et al., and Proteus melanovogenes Miles \& Halnan, and their relation to the genus Aeromonas Kluyver \& van Niel. J. gen. Microbiol. 5, 298.

MrLls, G. B. (1949). A biochemical study of Pseudomonas prunicola Wormald. I. Pectin esterase. Biochem. J. 44, 302.

Munoz, J., Scherago, M. \& Weaver, R. H. (1949). A serological study of members of the Pseudomonas genus. J. Bact. 57, 269.

Naylor, J. (1954). Studies on Plant Pathogenic Bacteria with Emphasis on Serological Identification. M.Sc. Thesis, University of Melbourne, 1954. 
Novel.r, A. (1953). New method of staining bacterial capsules in films and sections. Experientia, 9, 34.

O'MearA, R. A. Q. (1931). A simple rapid and delicate method of detecting the formation of acetylmethylcarbinol by bacteria fermenting carbohydrate. J. Path. Bact. 34, 401.

Oxford, A. E. (1944). Production of a soluble pectinase in a simple medium by certain plant pathogenic bacteria belonging to the genus Pseudomonas. Nature, Lond. 154, 271.

Palleroni, N. J. \& Doudoroff, M. (1957). Metabolism of carbohydrates by Pseudomonas saccharophila. III. Oxidation of D-arabinose. J. Bact. 74, 180.

Parker, C. A. (1955). Non-symbiotic nitrogen-fixing bacteria in soil. II. Studies on Azotobacter. Aust. J. Agric. Res. 6, 388.

Paton, A. M. (1958). Pectin-decomposing strains of Pseudomonas. Nature, Lond. $181,61$.

Proctor, M. H. \& Wirson, P. W. (1958). Nitrogen fixation by Gram-negative bacteria. Nature, Lond. 182, 891.

Rhodes, M. E. (1956). The Classification of Pseudomonas. Ph.D. Thesis, University of Reading.

Rhodes, M. E. (1957). The preservation of Pseudomonas under mineral oil. J. appl. Bact. 20, 108.

Rhodes, M. E. (1958). The cytology of Pseudomonas spp. as revealed by a silverplating staining method. J. gen. Microbiol. 18, 639.

St John-Brooks, R., Nain, K. \& Rhodes, M. (1925). The investigation of phytopathogenic bacteria by serological and biochemical methods. J. Path. Bact. 28, 203.

SANDIFord, B. R. (1987). Observations on Pseudomonas pyocyanea. J. Path. Bact. 44, 567.

Seleen, W. A. \& Stark, C. N. (1943). Some characteristics of green-fluorescent pigment-producing bacteria. J. Bact. 46, 491.

Shank, J. L., Chmura, N. W. \& Silliker, J.H. (1958). The production of fluorescent pigment by Bacillus subtilis. Bact. Proc. p. 11.

Sherwood, N. P., Johnson, T. L. \& Radotincky, I. (1926). Studies on Bacillus pyocyaneus. Kans. Univ. Sci. Bull. 15, 91.

Shewan, J. M., Hodgriss, W. \& Liston, J. (1954). A method for the rapid differentiation of certain non-pathogenic, asporogenous bacilli. Nature, Lond. 173, 208.

ShiLo, M. \& Stanier, R. Y. (1957). The utilization of tartaric acids by pseudomonads. J. gen. Microbiol. 16, 482.

SIERRA, G. (1957 a). A simple method for the detection of lipolytic activity of microorganisms and some observations on the influence of the contact between cells and fatty substrates. Leeurwenhoek ned. Tijdschr. 23, 15.

Sierra, G. (1957 b). Studies on bacterial esterases. Part I. Differentiation of a lipase and two ali-esterases during the growth of Pseudomonas aeruginosa and some observations on growth and esterase inhibition. Leeuwenhoek ned. Tijdschr. 23, 241.

Srmon, R. D. (1956). The use of fermentation reactions and pigment production to differentiate between types of Pseudomonas pyocyanea and other Pseudomonas species, especially fluorescens. Brit. J. exp. Path. 37, 494.

Smirh, W. K. (1958). A survey of the production of pectic enzymes by plant pathogenic and other bacteria. J. gen. Microbiol. 18, 33.

SNeath, P. H. A. (1956a). Cultural and biochemical characteristics of the genus Chromobacterium. J. gen. Microbiol. 15, 70.

SNeath, P. H. A. (1956b). The change from polar to peritrichous flagellation in Chromobacterium spp. J. gen. Microbiol. $15,99$. 
SNEATH, P. H. A. (1957a). Some thoughts on bacterial classification. J. gen. Microbiol. 17, 184.

Sneath, P. H. A. (1957b). The application of computers to taxonomy. J. gen. Microbiol. 17, 201.

Stanier, R. Y. (1942). The Cytophaga group. Bact. Rev. 6, 143.

Stanier, R. Y. (1947). Acetic acid production from ethanol by fluorescent pseudomonads. J. Bact. 54, 191.

Stapp, C. (1955). Zur Pathogenität fluorescierender Bakterien. Beitr. Biol. Pfl. 31, 515.

SteEL, R. \& W WLKER, T. K. (1957). A comparative study of cellulose-producing cultures and celluloseless mutants of certain Acetobacter spp. J.gen. Microbiol. $17,445$.

Steveninck, R. F. M. van (1958). Straight-growth inhibitors in glucose. Nature, Lond. 182, 950.

Suire, A. (1958). Recherches sur la dissociation spontanée des Pseudomonas. Ann. Inst. Pasteur, 94, 351.

TanNer, F. W. (1918). A study of the green fluorescent bacteria from water. J. Bact. $3,63$.

Thornberry, H. H. (1938). Pectase activity of certain micro-organisms. Phytopathology, 28, 202.

Topley and Wilson's Principles of Bacteriology and Immunity (1955), vol. 1. 4th ed. Eds. G. S. Wilson and A. A. Miles. London: Arnold.

Williamson, C. K. (1956). Morphological and physiological considerations of colonial variants of Pseudomonas aeruginosa. J. Bact. 71, 617.

ZoBeLr, C. E. (1932). Factors influencing the reduction of nitrates and nitrites by bacteria in semi-solid media. J. Bact. $24,273$.

(Received 26 February 1959) 